Review Article

\title{
Pretreatment Methods of Ligno - Cellulosic Biomass: A Review
}

\author{
Aritra Das*, Chanchal Mondal and Shyamal Roy \\ Department of Chemical Engineering, Jadavpur University, Kolkata - 700032, West Bengal, India.
}

Received 29 September 2015; Accepted 27 December 2015

\begin{abstract}
Present work primarily deals with the exhaustive investigations of rapid de-lignification processes from source-sorted organic fractions that are recalcitrant in nature. Organic solid wastes (OSW) belongs to the organic fraction of municipal solid wastes (MSW) and they act as enormous potential substrate for alternative source of energy in the form of bio-fuels. Nevertheless, these substrates are not easily biodegradable and the degree of biodegradability is solely dependent on the composition \& characteristic of organic solid wastes in municipal solid wastes. The component responsible for recalcitrance of organic solid wastes is lignin that occurs in variable amounts in different plant residues. In order to remove the recalcitrance from organic fraction municipal solid wastes and to make it more easily degradable by microbial consortia, certain pretreatment techniques have been adopted and they are applied either individually or in combined way for enhancement of bio-methanation i.e anaerobic digestion (AD) process. The goal of pretreatment method is to make the cellulose in micro-fibrils available for hydrolysis and improve the rate of hydrolysis. This paper reviews pretreatment techniques including physical, physico-chemical, chemical, biological methods respectively. The various effects of pretreatment on organic solid wastes are discussed separately and pretreatment methods have been compared on the basis of cost, efficiency and suitability to substrate.
\end{abstract}

Keywords: Organic solid wastes, lignin, pretreatment, hydrolysis, municipal solid waste, recalcitrance.

\section{Introduction}

Rapid population growth, increase in energy demand and global warming led to the scope of further research to enhance the availability of alternative sources of energy at a faster rate and less cost. Organic sources are available in abundance in the environment to be successfully converted to bio-fuel and holds great potential as a substitute to fossil fuels. Less dependency on fossil fuels\& more use of biofuels will not only help in conservation of fossil fuels but also indulge in less pollution and incur in less investments compared to fossil fuels. Many researchers have reported that bio-fuels from organic solid wastes have great potential as a substitute for gasoline. Likewise biogas has been regarded as a promising alternative source of energy that can be utilized for combined heat \& power generation, liquefaction of biogas to methanol, compressed biogas to be used similarly as fuels for car like compressed natural gas and purified biogas can be fed into gas distribution grids [1], [2].

Anaerobic digestion is one of the ancient \&well studied techniques for conversion of biomass to bio-fuel namely biogas (collectively methane \&carbon dioxide) [3]. Among all the treatment techniques, anaerobic digestion is regarded as the best suitable process for stabilization of organic solid wastes [4], due to its very low environmental

\footnotetext{
* E-mail address:aritra@research.jdvu.ac.in ISSN:1791-2377@ 2015 Kavala Institute of Technology. All rights reserved.
}

impact[4],[5],[6],[7] and higher energy recovery potential [4],[5],[8].Though anaerobic digestion was earlier implemented as waste treatment process but in the later years energy recovery from wastes gained higher importance.Anaerobic digestion refers to a process where organic matter is readily degraded synergistically by anaerobic microbial consortium in absence of oxygen to generate methane $\left(\mathrm{CH}_{4}\right)$ and carbon dioxide $\left(\mathrm{CO}_{2}\right)$, collectively called biogas. Four main steps associated with anaerobic digestion process are hydrolysis, acidogenesis, acetogenesis and methanogenesis. Many researchers have reported that the rate limiting step of anaerobic digestion process is hydrolysis [9] due to formation of toxic products(heterocyclic compounds\& volatile fatty acids) that are inhibitory to anaerobes. For easily biodegradable substrates, methanogenesis is the rate limiting step [10], [11].

Organic solid wastes include lingo-cellulosic biomass, food wastes $(\mathrm{FW})$, waste water treatment plant sludge etc. Food waste is the largest fraction of municipal solid wastes. A study by Food and Agricultural Organization(FAO,2011) predicted that by 2025 , food waste and municipal solid wastes will increase by 51 and $44 \%$ due to improper solid waste management for which global warming is a rising issue of the world. FAO also determined that by 2025 global methane production will amount to about 3 to $48 \mathrm{G} \mathrm{Kg}$. About one-third of food produced for humans in the world is lost or wasted globally and amounts to about 1.3 billion ton per year. Henceforth it is important to minimize food wastes and also develop certain sustainable treatment and management schemes [12], [13]. 
Aritra Das, Chanchal Mondal and Shyamal Roy/

Journal of Engineering Science and Technology Review 8 (5) (2015) 141-165

Lignocellulosic matter is profoundly found in areas of agricultural produce like widespread corn and wheat production etc. Leaves and yard wastes are major lignocellulosic wastes available with very less or almost negative cost associated with them. These materials are better in respect of compliance with feedstock collection and transportation. Compared to other organic matter, these are low in moisture content. As food wastes have higher moisture content, it is readily biodegradable andperfect substrate for anaerobic digestion process [14],[15].A wide array of organic solid wastes such as food waste, municipal solid wastes and animal manure have been tested as feedstocks in anaerobic digestion. Lignocellulosic matter including agricultural crops \& forestry residues, energy crops have largely gained attention as suitable feedstocks for anaerobic digestion due to their profound availability and increased needs of energy [16].About $90 \%$ of dry weight of most plant material is stored in the form of cellulose, hemicellulose, lignin and pectin. Lignin is complex polymer of aromatic alcohol known as monolignol \& the slowest decomposing component found in the integral cell wall of plants and some algae and responsible for strengthening of xylem cells. Most of the lignin turns into humus on full decomposition. Moreover, lignin is the only polymer found in plant cell wall that is not composed of monomeric carbohydrate units. It is tasteless, fibrous material insoluble in water and alcohol but soluble in weak alkaline solutions and can be precipitated from solution using acids. Lignin fills in the space between cell walls \& cellulose, hemicellulose and pectin components and at the same time it is covalently bonded to hemicellulose and cross links other plant polysaccharides. There are certain physicochemical factors that hinder the biodegradability of biomass and thereby affect in yield of hydrolytic product and further lead to overall negative impact on biomethanation process. There is a general agreement in the literature that presence of lignin affects biodegradability but till now quantitative relationship between biodegradability and lignin content is not well understood and data are inconclusive [17]. A few studies reported strong negative linear correlation between lignin content and biodegradability of lignocellulosic biomass [17]. A study on anaerobic digestion of herbacious materials, animal manures and newspaper reported inverse linear relationship between volatile solid (VS) destruction with a correlation coefficient $\left(\mathrm{r}^{2}\right)$ of 0.94 [18]. A study involving short term $48 \mathrm{~h}$ digestion of over 100 different lignocellulosic biomass samples by rumen microbes reported weak inverse linear relationship $\left(\mathrm{r}^{2}=0.75\right)$ between lignin content and volatile solid destruction [19].Another study reported poor linear correlation $\left(r^{2}=0.59-0.69\right)$ lignin content and methane conversion efficiency of seven different types of lignocellulosic biomass including two batches of wheat straw, corn stover, napier grass wood grass, newpaper and white fir, at a total solids (TS) content of less than $1 \%[20]$.

Cellulose and hemicellulose of biomass should be broken down to yield their corresponding monomers (sugars), to make it available for the microbes. Hemicellulose can be subjected to dilute acid hydrolysis, but more extreme conditions are needed for hydrolysis of cellulose. The reaction is carried out at high temperature $\left(160^{\circ}-230^{\circ} \mathrm{C}\right)$, acid concentration at $2-5 \%$ and pressure $(10$ atm) although glucose yield is low [21]. Compared to this, concentrated acid $(10-30 \%)$ hydrolysis is carried out at lower temperature $\left(<50^{\circ} \mathrm{C}\right)$, needs longer retention times but results in better yield of glucose [22].
In order to improve the digestibility of cellulose, biomass needs to be pretreated to expose the cellulose in plant fibersto acids or microbial enzymes to break down to constituent sugars. Different pretreatment techniques have been implemented so far including mechanical communition, pyrolysis, ammonia fiber explosion, $\mathrm{CO}_{2}$ explosion, steam explosion, alkaline pretreatment, biological pretreatment, dilute and concentrated acid pretreatment etc. Nevertheless, pretreatment is the most cost effective process prior to $\mathrm{AD}$, but it has great potential for improvements in efficiency and lowering of cost through further research and development[23],[24],[25],[26],[27].

\section{Properties of Lignocellulosic Biomass}

The properties of lignocellulosic biomass are always mentioned in terms of proximate, ultimate and compositional analysis (carbohydrates, fats, proteins, cellulose and hemicellulose) and these are of importance to any biomass to bio-fuel conversion process. Biomass feedstocks exhibit a wide range of physical and chemical properties but despite their availability from different sources, they possess uniformity in their fuel properties.

\subsection{Proximate properties}

Generally air-dried biomass contains 15-20 \% moisture. Rest of the portion is total solids (TS) content in biomass. Total solid is composed of volatile solids (VS) and a little fraction as mineral content (ash). In any kind of energy conversion process, only a part of VS undergoes conversion. Table 1 represents the proximate properties of major lignocellulosic agricultural wastes.

Table 1. Proximate properties of common agricultural lignocellulosic biomass

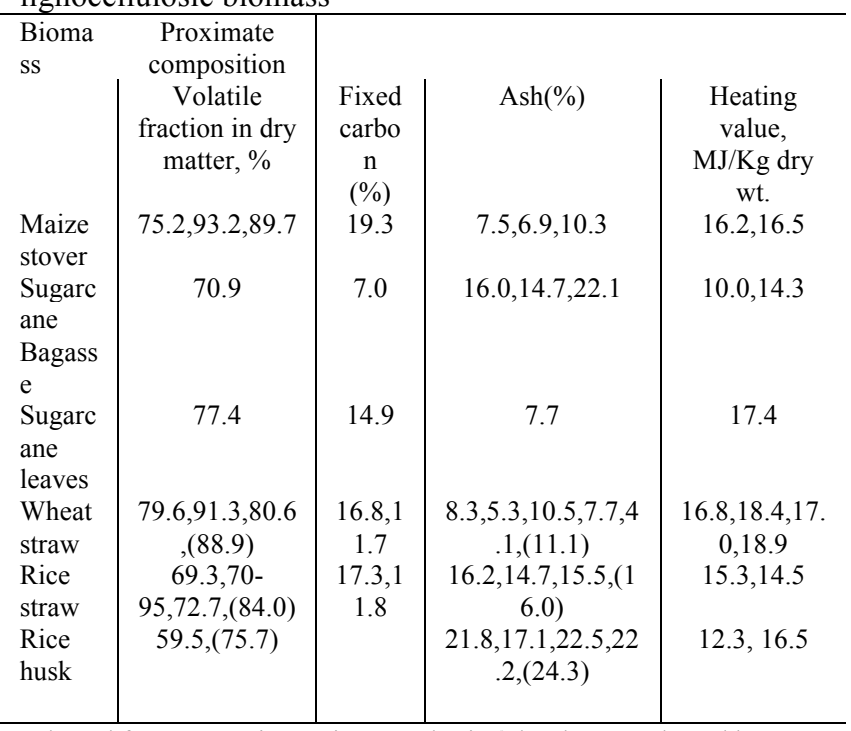

Adapted from [29]. Figures in parenthesis () has been evaluated by authors of [29]

\subsection{Ultimate properties}

Major part of biomass is carbon, oxygen and hydrogen. in general, biomass contains $40-45 \%$ mass as oxygen, $35-50 \%$ mass as carbon on dry weight basis of biomass. The ultimate properties of biomass govern the quality and quantity of product derived in any biomass to biofuel conversion process. Table 2 shows the ultimate properties of some of the major lignocellulosic agricultural wastes 
Aritra Das, Chanchal Mondal and Shyamal Roy/

Journal of Engineering Science and Technology Review 8 (5) (2015) 141-165

Table 2. Ultimate properties of common agricultural lingocellulosic biomass.

\begin{tabular}{|c|c|c|c|c|c|}
\hline Bioma & \multicolumn{5}{|c|}{ Elemental Composition } \\
\hline ss & Carbon, $\%$ & $\begin{array}{l}\text { Hydrogen, } \\
\%\end{array}$ & $\begin{array}{l}\text { Oxygen, } \\
\%\end{array}$ & $\begin{array}{l}\text { Nitrog } \\
\text { en, } \%\end{array}$ & $\begin{array}{l}\text { Sulp } \\
\text { hur, } \\
\%\end{array}$ \\
\hline $\begin{array}{l}\text { Maize } \\
\text { straw }\end{array}$ & 45.6 & 5.4 & 43.4 & 0.3 & 0.04 \\
\hline $\begin{array}{l}\text { Maize } \\
\text { stover }\end{array}$ & $43.7,35.2$ & 5.6 & 43.3 & 0.6 & 0.01 \\
\hline $\begin{array}{l}\text { Sugar } \\
\text { cane } \\
\text { leaves }\end{array}$ & 39.7 & 5.55 & 46.8 & 0.2 & - \\
\hline $\begin{array}{l}\text { Wheat } \\
\text { straw }\end{array}$ & $\begin{array}{l}46.7,45.5,(45 . \\
8)\end{array}$ & $6.3,5.1,(6)$ & $41.2,34.1$ & $\begin{array}{l}0.4,(0 . \\
42)\end{array}$ & 0.1 \\
\hline $\begin{array}{l}\text { Rice } \\
\text { straw }\end{array}$ & $41.8,36,(41)$ & $\begin{array}{l}4.6,5.3,(5.4 \\
)\end{array}$ & $36.6,43.1$ & $\begin{array}{l}0.7,0.3 \\
5- \\
0.70,(0 \\
.74)\end{array}$ & 0.08 \\
\hline $\begin{array}{l}\text { Rice } \\
\text { husk }\end{array}$ & $\begin{array}{l}37.9,44.6,38 . \\
2,(36.3)\end{array}$ & $\begin{array}{l}4.82,5.6,5 . \\
6,(4.7)\end{array}$ & $\begin{array}{l}34.9,49.3 \\
, 33.7\end{array}$ & $\begin{array}{l}0.43,(0 \\
.60)\end{array}$ & 0.17 \\
\hline
\end{tabular}

Adapted from [29]. Figures in parenthesis () has been evaluated by authors of [29]

\subsection{Compositional properties}

The composition of various constituents (cellulose, hemicellulose \& lignin) varies with different plant species. Further ratio of other constituents in plant species vary with age, stages of growth [28]. Table 3 represents the cellulose, hemicellulose \& lignin content of residues.

Table 3. Cellulose, hemicellulose \& lignin content of common agricultural residues

\begin{tabular}{|c|c|c|c|}
\hline $\begin{array}{l}\text { Lignocellulosic } \\
\text { matter }\end{array}$ & Cellulose (\%) & $\begin{array}{c}\text { Hemicellulose } \\
(\%)\end{array}$ & Lignin (\%) \\
\hline $\begin{array}{l}\text { Hardwood } \\
\text { stems }\end{array}$ & $40-55$ & $24-40$ & $18-25$ \\
\hline Softwood stems & $45-50$ & $25-35$ & $25-35$ \\
\hline Nut shells & $25-30$ & $25-30$ & $30-40$ \\
\hline Corn cobs & 45 & 35 & 15 \\
\hline Grasses & $25-40$ & $35-50$ & $10-30$ \\
\hline Paper & $85-99$ & 0 & $0-15$ \\
\hline Wheat straw & 30 & 50 & 15 \\
\hline Sorted refuse & 60 & 20 & 20 \\
\hline Leaves & $15-20$ & $80-85$ & 0 \\
\hline $\begin{array}{l}\text { Cotton seed } \\
\text { hairs }\end{array}$ & $80-95$ & $5-20$ & 0 \\
\hline Newspaper & $40-55$ & $25-40$ & $18-30$ \\
\hline $\begin{array}{l}\text { Waste paper } \\
\text { from chemical } \\
\text { pulps }\end{array}$ & $60-70$ & $10-20$ & $5-10$ \\
\hline $\begin{array}{l}\text { Primary waste } \\
\text { water solids }\end{array}$ & $8-15$ & & \\
\hline $\begin{array}{l}\text { Solid cattle } \\
\text { manure }\end{array}$ & $1.6-4.7$ & $1.4-3.3$ & $2.7-5.7$ \\
\hline $\begin{array}{l}\text { Coastal } \\
\text { bermudagrass }\end{array}$ & 25 & 35.7 & 6.4 \\
\hline Switchgrass & 45 & 31.4 & 12 \\
\hline Swine waste & 6.0 & 28 & $\mathrm{Na}$ \\
\hline
\end{tabular}

Adapted from [30]

Many properties of cellulose depend on its degree of polymerization (DP) i.e the number of glucose molecules that make up one polymer molecule [79]. Generally cellulose obtained from wood pulp has a DP between 300 and 1700 [79]. DP of cellulose can extend to a value of 17000 [221]. Cellulose occurs in an organized fibrous network within plant cell wall and it is the main structural constituent. The structure of cellulose is depicted in fig.1. Cellulose occurs in both crystalline and amorphous forms in plant cell wall (fig. 2). Mostly it occurs in crystalline form though a small portion of unorganized chains of cellulose [79], appear in amorphous form. Cellulose is more susceptible to enzymatic degradation in amorphous form. So, crystallinity index is an important issue with lignocellulosic biomass degradation. Moreover, cellulose is a linear polysaccharide polymer of glucose ( $\beta-1,4$-glucan) made of cellobiose units. The long chain cellulose polymer are linked to each other by hydrogen and Vander Waals bonds so called "elementary and micro-fibrils" [79]. The hydrogen bonding allows the parallel arrangement of cellulose polymer chains. These fibrils are further linked together by hemicelluloses and bonded together by lignin [34],[35],[36],[37].

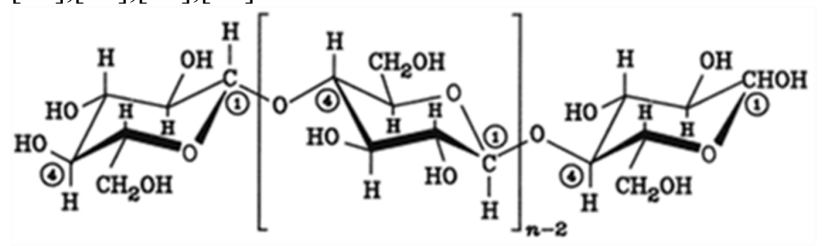

Fig. 1 Structure of single cellulose molecule [79]

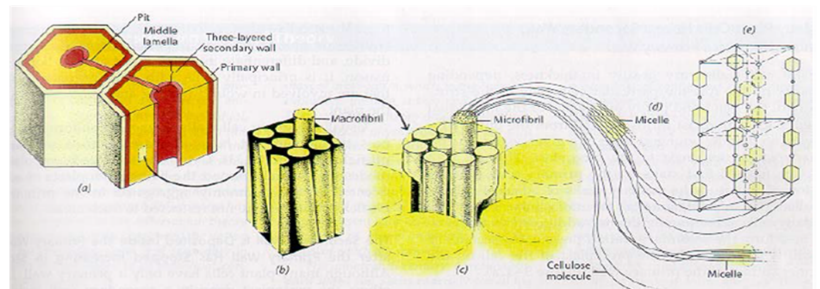

Fig. 2 Formation of macro- and microfibrils (fibers) of cellulose and their position in the wall [79]

Cellulose is hygroscopic in nature and under normal conditions of temperature $\left(20^{\circ} \mathrm{C}, 60 \%\right.$ relative humidity $)$ and atmospheric pressure, it absorbs $8-14 \%$ water [79]. Nevertheless, cellulose is insoluble in water when it swells. Cellulose is also insoluble in dilute acid solutions at low temperature. Solubility of cellulose is strongly related to the degree of hydrolysis achieved. By applying higher temperatures, it is possible to solubilize cellulose as the energy provided is sufficient to break the hydrogen bond that holds the crystalline structure of the molecule (fig. 3).

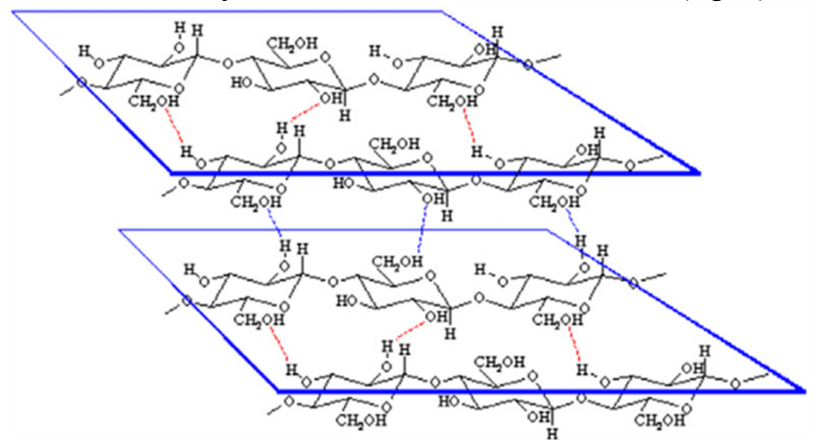

Fig. 3 Demonstration of the hydrogen bonding that allows the parallel arrangement of the cellulose polymer chains [79].

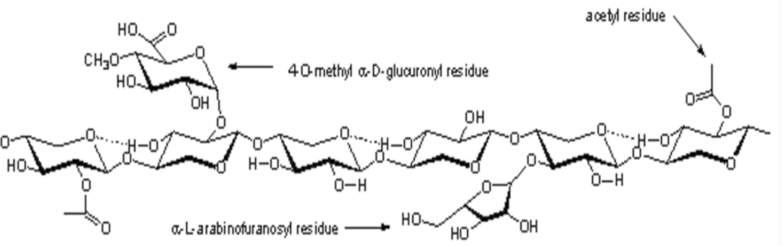

Fig. 4 A schematic representation of hemicellulose obtained from plants [79] 
Aritra Das, Chanchal Mondal and Shyamal Roy/

Journal of Engineering Science and Technology Review 8 (5) (2015) 141-165

Table 4. Reviews on different pretreatment methods to enhance AD using various substrates

\begin{tabular}{|c|c|c|}
\hline & Pretreatment methods & $\begin{array}{c}\text { Important } \\
\text { findings }\end{array}$ \\
\hline OFMSW & All pretreatment methods & $\begin{array}{l}\text { Physical } \\
\text { pretreatments are } \\
\text { widely applied for } \\
\text { OFMSW, whereas } \\
\text { other methods are } \\
\text { not spread at } \\
\text { industrial level. }\end{array}$ \\
\hline $\begin{array}{l}\text { All organic } \\
\text { substrates }\end{array}$ & All pretreatment methods & $\begin{array}{l}\text { The most popular } \\
\text { pretreatment } \\
\text { methods are } \\
\text { thermal and } \\
\text { ultrasonic for } \\
\text { WWTP sludge, } \\
\text { chemical for } \\
\text { lignocellulosic } \\
\text { substrates and } \\
\text { mechanical for } \\
\text { OFMSW. }\end{array}$ \\
\hline $\begin{array}{l}\text { Lignocellulos } \\
\text { ic substrates }\end{array}$ & $\begin{array}{l}\text { Thermal,thermo-chemical, } \\
\text { chemical }\end{array}$ & $\begin{array}{l}\text { Pretreatments } \\
\text { could improve the } \\
\text { digestibility of } \\
\text { lignocellulosic } \\
\text { substrates. } \\
\text { Thermal } \\
\text { pretreatments as } \\
\text { well as lime and } \\
\text { ammonia based } \\
\text { chemical methods } \\
\text { are more effective } \\
\text { in improving the } \\
\text { digestibility of } \\
\text { lignocellulosic } \\
\text { substrates. }\end{array}$ \\
\hline $\begin{array}{l}\text { Pulp\&paper } \\
\text { sludge }\end{array}$ & $\begin{array}{l}\text { Thermal,thermo- } \\
\text { chemical,chemical }\end{array}$ & $\begin{array}{l}\text { Pretreatments } \\
\text { could result in } \\
\text { reduced HRT, } \\
\text { increased methane } \\
\text { production and } \\
\text { reduced sludge } \\
\text { size. }\end{array}$ \\
\hline $\begin{array}{l}\text { WWTP } \\
\text { sludge }\end{array}$ & $\begin{array}{l}\text { Ultrasound,chemical,thermal,the } \\
\text { rmo-chemical, microwave }\end{array}$ & $\begin{array}{l}\text { Pretreatments } \\
\text { result in enhanced } \\
\text { biogas } \\
\text { production }(30 \text { - } \\
50 \%) \\
\text { Pretreatments } \\
\text { could yield a } \\
\text { better digestate } \\
\text { with high } \\
\text { recoverable } \\
\text { nutrients } \\
\text { Thermal } \\
\text { pretreatment at } \\
\text { high } \\
\text { temperature }>175^{\circ} \\
\text { C) as well as } \\
\text { thermo-chemical } \\
\text { methods are more } \\
\text { effective } \\
\text { improving sludge } \\
\text { dewaterability. }\end{array}$ \\
\hline
\end{tabular}

The coalescence of several polymer chains leads to the formation of microfibrils, which in turn are united to form fibres. In this fashion cellulose can obtain a crystalline structure. 0 illustrates the structure as well as the placement of cellulose in the cell wall [79]. The term hemicellulose is a collective term used to represent a family of polysaccharides namely arabino-xylans, gluco-mannans, galactans and others that are found in the plant cell wall and have different composition and structure depending upon their source and the extraction method [79]. The most common type of polymer that belongs to the hemicelluloses family of polysaccharide is the xylan. A molecule of xylan involves 1:4 likages of xylopyranosyl units with $\alpha-(4-\mathrm{O})$-methyl-Dglucuronopyranosyl units attached to anyhydroxylose units and to a lesser extent six carbon sugar monomers such as glucose. Hemicellulose (fig. 4) is insoluble in water at low temperature, however its hydrolysis starts at a temperature lower than that of cellulose i.e; cellulose requires much higher temperature for solubility ${ }^{\mathrm{V}}$. Presence of acid highly improves the solubility of hemicelluloses in water. The hemicelluloses extracted from plants exhibit higher degree of polydispersity and polymolecularity (a broad range of size, shape and mass characteristics). However, the degree of polymerization doesnot exceed 200 units whereas minimum limit can be around 150 monomers.

Lignin is a very complex large molecule (fig.5 \& 6) constructed of phenolic monomer units linked in a three dimensional structure. Three phenyl propionic alcohols exist as monomers of lignin: (i) coniferyl alcohol (guaiacyl propanol) (ii) coumaryl alcohol (p-hydroxyphenol propanol), and (iii) sinapyl alcohol (syringyl alcohol). Akyl-aryl, alkylalkyl and aryl-aryl ether bonds links these phenolic monomers together.
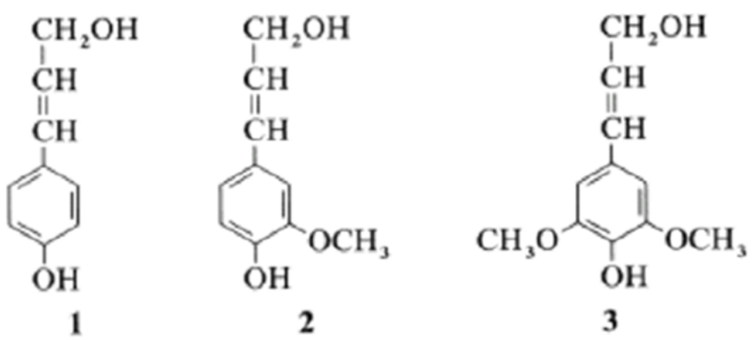

Fig.5 Dominant building blocks of three-dimensional polymer lignin (1) P-coumaryl, (2) Coniferyl-, (3) Sinapyl alcohol [79]

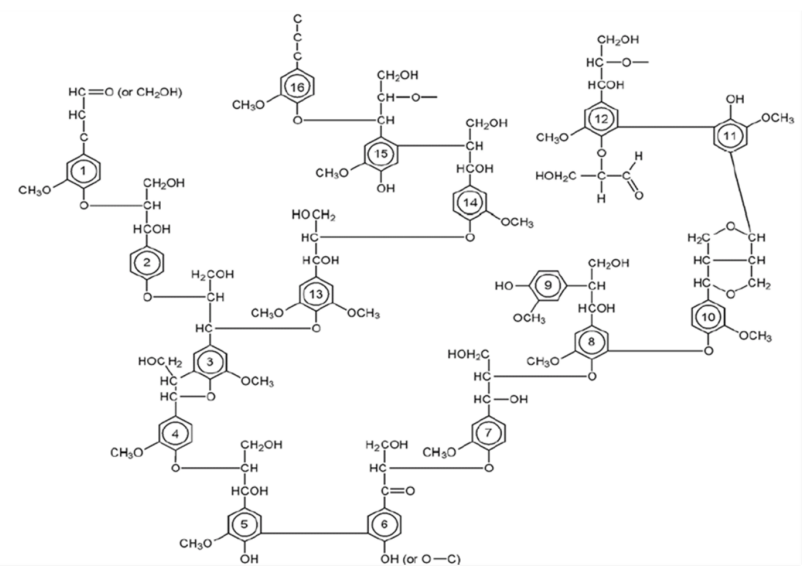

Fig.6 A schematic diagram of lignin obtained from spruce [79].

In general herbaceous plants such as grasses have the lowest impermeable and is one of the major drawbacks of using lignocellulosic materials in fermentation, as it makes lignocellulose resistant to chemical and biological degradation [38],[39],[40]. Dividing higher plants into two categories, hardwood (angiosperm) and softwood (gymnosperm), it has been identified that lignin from softwood is made up of more than $90 \%$ coniferyl alcohol and the rest being mainly p-coumaryl alcohol units. Just as hemicellulose, lignin also exhibit polydispersity. Branching and bonding is observed between similar molecules. 0 
Aritra Das, Chanchal Mondal and Shyamal Roy/

Journal of Engineering Science and Technology Review 8 (5) (2015) 141-165

presents a model structure of lignin from spruce pine. Lignin in wood behaves as three dimensional network. It plays an important role in the cell's development and endurance. It acts as binder between cells creating a composite material that has a remarkable resistance to impact, compression and bending [79]. Certains solvents have been identified to solubilize lignin namely, low molecular alcohols, dioxane, acetone, pyridine and dimethyl sulfoxide. Elevated temperatures cause thermal softening of lignin which allows depolymerization reactions of acidic or alkaline nature to accelerate [80].
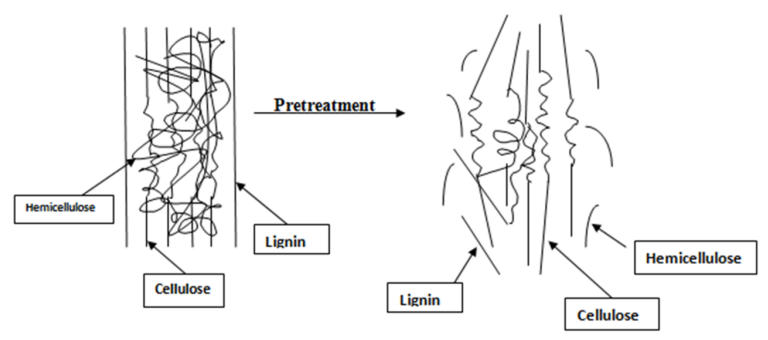

Fig.7 Schematic diagram of the role of pretreatment in conversion of biomass to bio-fuel [41]

\section{Degradation of cellulose, hemicellulose and extractives}

A study reported degradation of cellulose, hemicellulose and extractives during 30-day solid state - anaerobic digestion at an $\mathrm{S} / \mathrm{I}$ ratio of 2 is presented in the following figures $8,9 \&$ 10 [17]. Compositional analysis has been done on samples at the beginning and day 30 of the solid state - anaerobic digestion process [17]. Highest cellulose degradation of $41 \%$ was observed for solid state - anaerobic digestion of corn stover, $36 \%$ for wheat straw, $16 \%$ for leaves and $6 \%$ for yard wastes [17]. Similarly, hemicellulose degradation was $34 \%$ for corn stover, $35 \%$ for wheat straw, $21 \%$ for leaves and $7 \%$ for yard wastes [17]. It was clearly noted that cellulose and hemicellulose degradation was negatively related to lignin content of lignocellulosic biomass [17]. Lignin is one of the key factors controlling the performances of solid state - anaerobic digestion of lignocellulosic biomass.

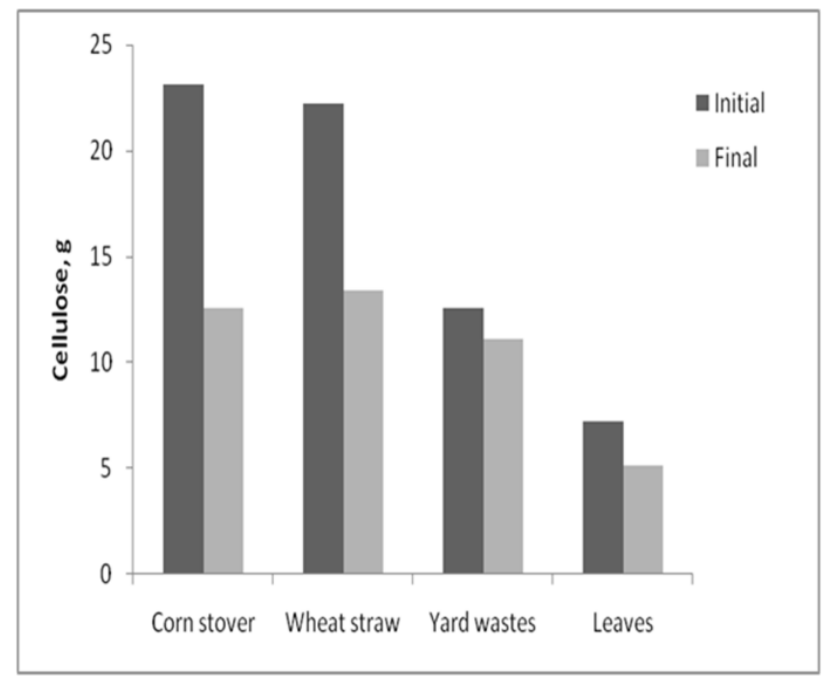

Fig 8. Degradation of cellulose [17]

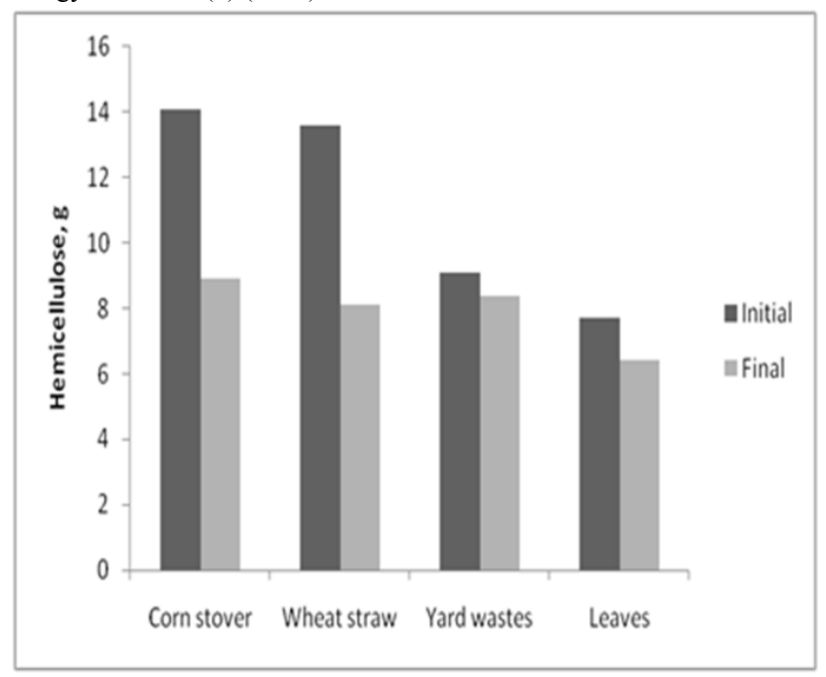

Fig 9. Degradation of hemicelluloses [17]

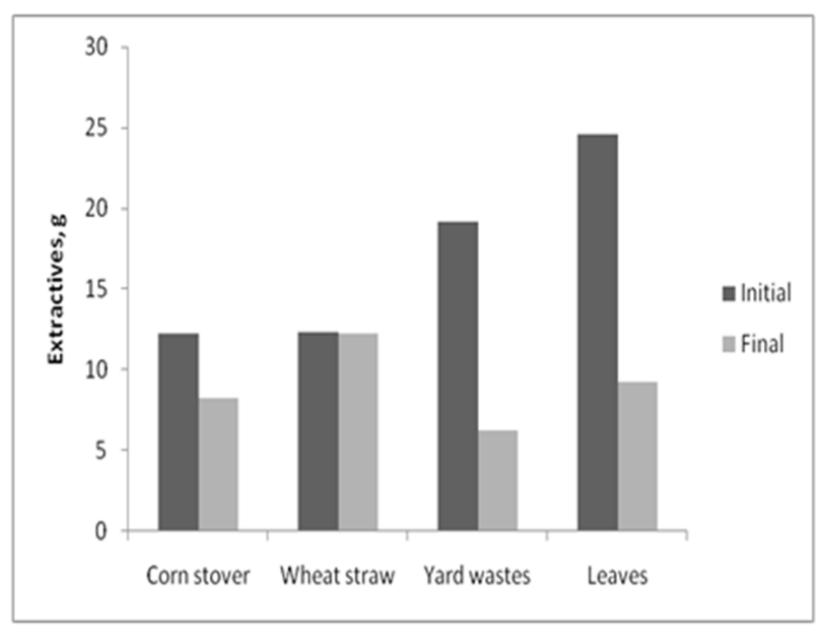

Fig 10.Degradation of extractives [17]

A different trend was observed in the degradation of extractives. Highest degradation of extractives was observed in leaves $(57 \%)$ followed by yard waste $(56 \%)$, corn stover $(14 \%)$ and wheat straw (0\%) [17]. Due to low cellulose and hemicellulose degradation of leaves and yard wastes, it is likely considered that extractives was the main contributor to the total biogas generation from leaves and yard wastes [17]. However, it is really not possible to correlate fully regarding biogas contributors as cellulose, hemicellulose and extractives, due to heterogeneous nature of lignocellulosic wastes [17].

\section{Goals of pretreatment process}

There are certain goals of pretreatment like breakage of lignin, disruption of cellulose crystallinity and increase porosity of lignocellulosic materials [23]. Pretreatment must also meet some essential requirements like : (1) improve the formation of sugars or ability to form sugars by hydrolysis, (2) avoid degradation or loss of carbohydrates, (3) avoid formation of inhibitory by-products of hydrolysis and fermentation processes, (4) be cost-effective [41].

\section{Classification of pretreatment processes}

Pretreatment methods can be suitably classified into few kinds: physical (mechanical comminution i.e. milling, crushing/grinding), physicochemical (steam-explosion, 
Aritra Das, Chanchal Mondal and Shyamal Roy/

Journal of Engineering Science and Technology Review 8 (5) (2015) 141-165

AFEX etc), chemical (acid \& alkali pre-treatment), biological etc or a combination of all these [41]. Suitable pretreatment techniques are effective for specific biomass or waste. Hence, selection of technique is totally dependant on the priority of biomass.

\section{Pretreatment of lingo-cellulosic materials}

\subsection{Physical pretreatment}

Cellulose crystallinity can be reduced by the application of mechanical comminution including grinding or milling, chopping. The size of the particles obtained after chopping is $10-30 \mathrm{~mm}$ and it finally gets reduced to $0.2-2 \mathrm{~mm}$ after milling or grinding [42]. Ball mill or vibratory ball mill was further more effective in reducing cellulose crystallinity, improving their digestibility [43]. Mechanical pretreatments (fig.11) such as rotary drums have been used as an effective technology for organic fraction municipal solid waste separation and pretreatment prior to anaerobic digestion which could enhance the biogas production by $18-36 \%$ [44],[45]. A study reported small variations in both methane yields per gVS (gram volatile solids) and content of methane in biogas while studying the source-sorted organic fraction municipal solid wastes, pretreated with different mechanical methods like screw press, disc screen shredder, food waste disposer and piston press [46]. In a similar fashion, Zhang and Banks found no significant enhancement of bio-methane production using methods like screw press, piston press etc [47]. But a study by Hansen et al. reported that using screw press resulted in smaller particle size but shredder \& magnetic separation yielded in higher methane production [48]. A high pressure homogenizer (HPH) increases the pressure upto several hundred bar, then homogenizes the biomass under strong decompression [49]. Cavitation is formed that induces internal energy, which disrupts the cell membranes of organic wastes [50]. This kind of pretreatment methods are mostly suitable for lignocellulosic wastes, manure and waste water treatment plant sludge. Size reduction through bead mill, electroporation and liquefaction of organic fraction municipal solid wastes have been studied at lab scale. A study by Izumi et al. reported size reduction by bead mill followed by $40 \%$ higher COD solubilization, that led to $28 \%$ higher biogas production, but excess particle size reduction to $0.7 \mathrm{~mm}$ caused an accumulation of volatile fatty acids [51]. Methanogens are highly sensitive to acidic intermediates [52], so excess acid accumulation will lead to lowering of anaerobic digestion process performances.

Maceration, sonication (ultrasonication) and high pressure homogenizer are the simplest pretreatment methods for organic solid wastes such as lignocellulosic biomass and waste water treatment plant sludges. By applying maceration biogas production was enhanced by $10-60 \%$ [53]. Upon size reduction of lignocellulosic biomass, resulted in 5-25\% increased hydrolysis yield, solely depending upon the prior mechanical pretreatment used [52]. Similarly, maceration of fibers in manure upto $2 \mathrm{~mm}$ resulted in $16 \%$ increased yield of biogas and further $20 \%$ increased yield was obtained with $0.35 \mathrm{~mm}$. Further reduction of particle size resulted in no significant enhancement in yield of biogas [54]. Sonication before anaerobic digestion process resulted in 24-140\% enhanced biogas production in batch systems and $10-45 \%$ in continuous or semi-continuous systems [53]. High pressure homogenizer at $600 \mathrm{bar}$ resulted in complete disintegration of filaments [50]. Higher biogas production was mostly due to more extensive solubilization of the particulates. However, all pretreatment techniques does not always confirm the enhancement of volatile solid destruction and higher biogas production.
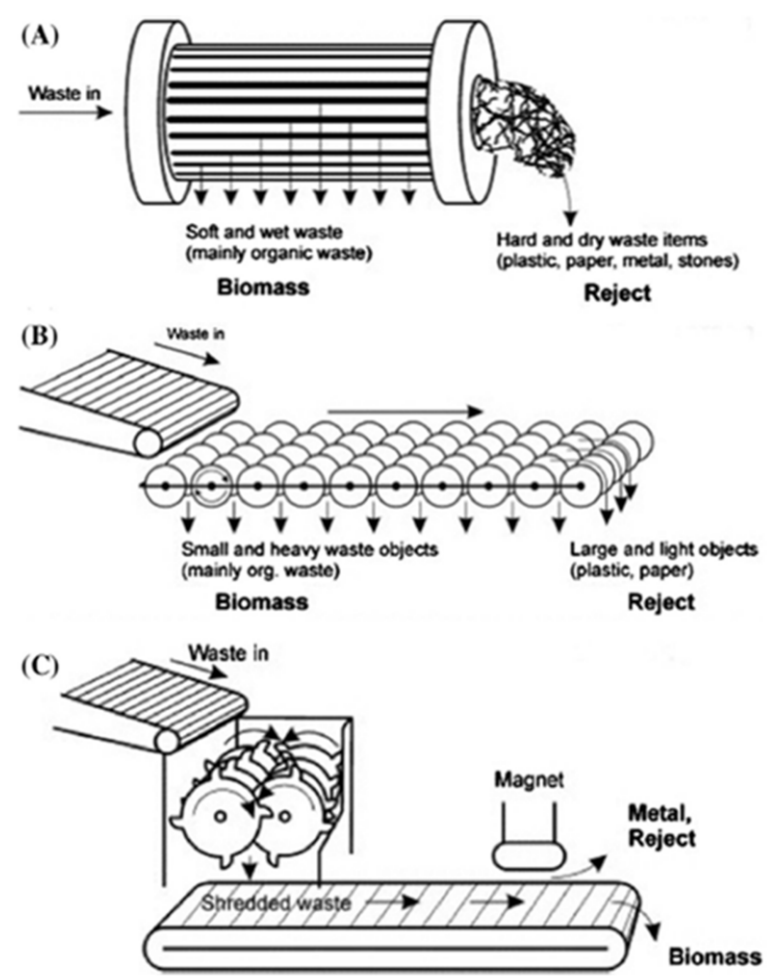

Fig. 11 Mechanical pre-treatment methods to enhance the AD of OFMSW: (A) Screw press; (B) disc screen; (C) shredder with magnet [57].

Certain advantages associated with physical pretreatment are no odour generation, an easy implementation, better dewaterability of biomass, less energy consumption. Disadvantages are equipment clogging and scaling and no effect on pathogen removal [55], [56].

\subsection{Thermal pre-treatment}

Thermal pre-treatment technique have been successfully applied at both lab \& industrial scale for pathogen removal, reduction of viscosity of biomass and easy dewatering of biomass/waste [5],[12],[58],[59],[60],[61]'. The main effect of thermal treatment is disintegration of cell membranes of biomass/waste that leads to solubilization of organic compounds, i.e macromolecules are broken down to micromolecules [62],[63],[64],[65]. Some studies reported better potential of organic compounds solubilization at lower temperatures, but essentially longer pre-treatment times are needed [57]. Different temperature ranges $\left(50-250^{\circ} \mathrm{C}\right)$ to enhance anaerobic digestion of different organic solid wastes (waste water treatment plant sludges and lignocellulosic substrates) have been studied [57]. Different methods of heating like steam, electric and microwave have been studied [57]. A study by Mottet et al. reported that no significant difference was observed between steam and electric heating in solubilization of biopolymers but microwave heating showed better results [66]. Better rate of solubilization of biopolymers by microwave heating was due to polarization of macromolecules [55],[63]. Higher 
Aritra Das, Chanchal Mondal and Shyamal Roy/

Journal of Engineering Science and Technology Review 8 (5) (2015) 141-165

temperature treatments $\left(>160^{\circ} \mathrm{C}\right)$ of lignocellulosic wastes not only results in solubilization of hemicellulose but also solubilization of lignin [57]. Certain compounds are released which are mainly phenolic compounds and these are highly inhibitory to microbial consortium [67].

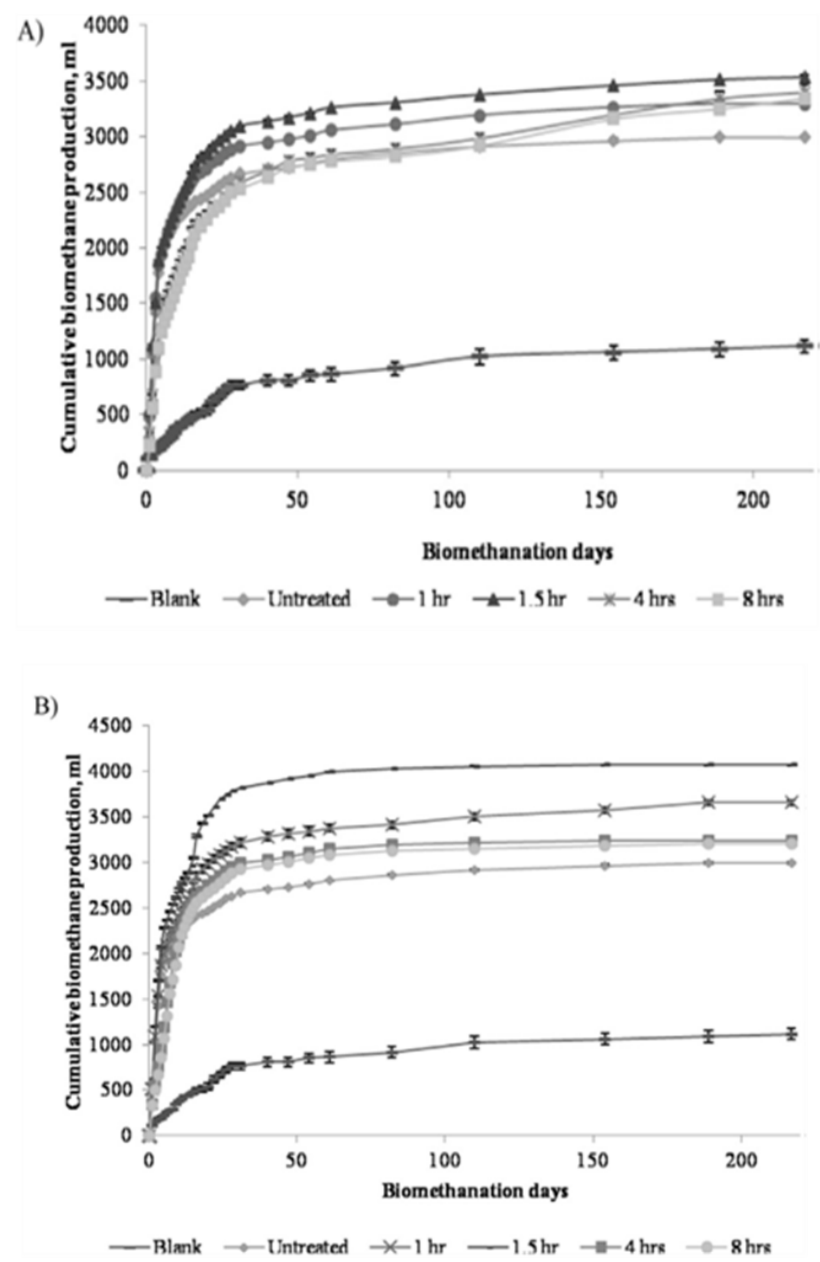

Fig 12. CBP curves of wastes pre-treated at (A) $70{ }^{\circ} \mathrm{C}$; and (B) $80{ }^{\circ} \mathrm{C}$ for various treatment times [74]

A study by Bougrier et al. suggested that pre-treatment at higher temperatures $\left(>170^{\circ} \mathrm{C}\right)$ leads to changes in color of the biomass/waste (mainly food waste) due to browning reaction (mallaird reaction) that occurs between carbohydrates and amino acids; these compounds are very complex in nature and difficult for the microbes to be biodegraded [68]. Specifically, one such complex compound is melanoidin that forms as a result of chemical bonding and particle agglomeration [68]. These limitations can occur due to prolonged treatment times at lower temperatures or pretreatment process carried out at temperatures exceeding $150^{\circ} \mathrm{C}[53],[67],[69],[70],[71]$.
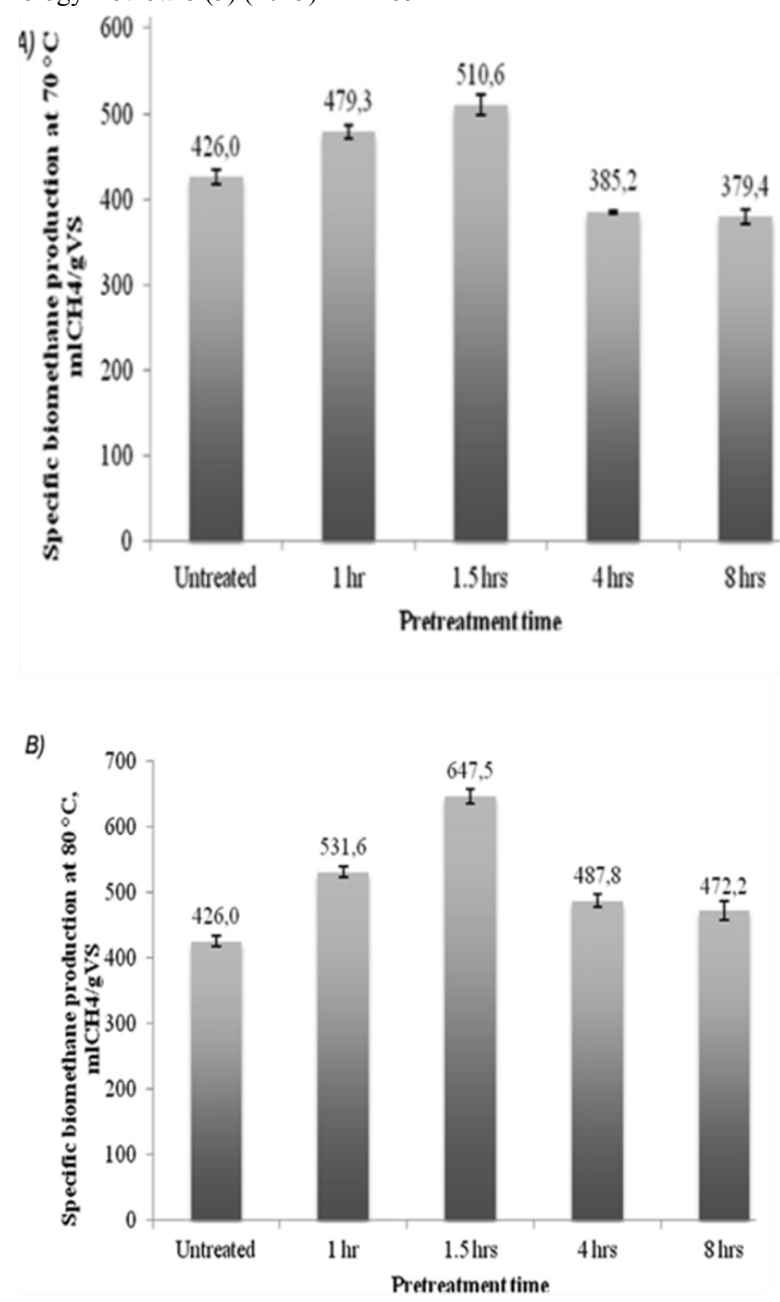

Fig. 13 Effect of (A) $70{ }^{\circ} \mathrm{C}$; and (B) $80{ }^{\circ} \mathrm{C}$ thermal time on biomethane production during initial 20 days of the BMP test [74]

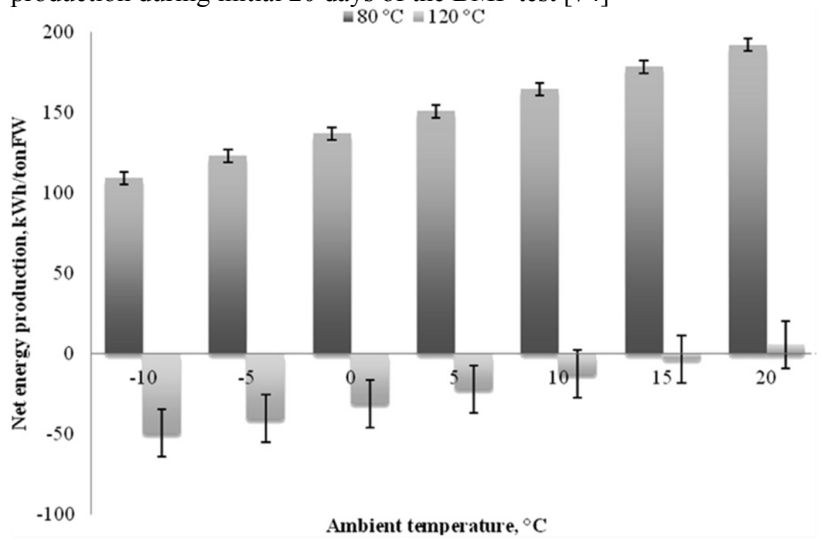

Fig. 13CEffect of ambient air temperature on the net energy production from thermal pretreatment at $80{ }^{\circ} \mathrm{C}$ for $1.5 \mathrm{~h}[74]$

\subsubsection{Thermal pre-treatment at higher temperature $\left(>110^{\circ} \mathrm{C}\right)$}

Some studies reported strong negative results with thermal pre-treatment at higher temperatures. Specially food wastes and fruit \& vegetable wastes suffered higher temperature thermal pre-treatment due to formation of melanoidins [61]. Pre-treatment at $175{ }^{\circ} \mathrm{C}$ for food waste and fruit \& vegetable wastes resulted in $7.9 \%$ and $11.7 \%$ decrease of biomethane production [61] whereas pre-treatment at $120{ }^{\circ} \mathrm{C}$ of food waste resulted in $24 \%$ increase of biomethane production [72]. Comparatively, a study on thermal pre-treatment of pig manure at $110{ }^{\circ} \mathrm{C}$ resulted in low biogas yield [73]. Hardening and darkening(brownish color development) of 
Aritra Das, Chanchal Mondal and Shyamal Roy/

Journal of Engineering Science and Technology Review 8 (5) (2015) 141-165

manure was observed which was due to occurence of mallaird reactions [73].

\subsubsection{Thermal pre-treatment at lower temperature $\left(<110^{\circ} \mathrm{C}\right)$} Thermal pre-treatment at lower temperatures of $70{ }^{\circ} \mathrm{C}$ and 80 ${ }^{0} \mathrm{C}$ have reported better specific biomethane yield considered for initial 20 days of anaerobic digestion process (fig 12,13) [74]. There is general agreement in the literatures that during initial 20 days of anaerobic digestion process, all degradable volatile solids (VS) are degraded and/or completely digested [74]. Cumulative biomethane yields for those processes are also higher [74]. Protot et al. suggested that thermal pretreatment at temperatures below $100{ }^{0} \mathrm{C}$ did not result in degradation of complex molecules, but it simply induces the deflocculation of macromolecules [64]. Thermal pretreatment resulted in increase in solubilization of proteins and increased removal of particulate carbohydrates. According to EU Regulation EC1772/2002 requires OSW to be pretreated at least an hour at $70{ }^{\circ} \mathrm{C}$ [57]. Similarly, EU Regulation EC1774/2002 dictates that $\mathrm{FW}$ is catering waste and should be pasteurized at $>70{ }^{\circ} \mathrm{C}$ for at least an hour or at $>133{ }^{0} \mathrm{C}$ for $20-30 \mathrm{~min}$ [74]. Several pre-treatment temperatures $\left(70-140{ }^{\circ} \mathrm{C}\right.$ for $1 \mathrm{~h}$ and $140-150{ }^{\circ} \mathrm{C}$ for $\left.30 \mathrm{~min}\right)$ have been applied at variable pre-treatment times of $1.5,4$ and $8 \mathrm{~h}$ respectively [74]. The net energy production was calculated based on the extra energy produced $\left(\mathrm{E}_{\text {produced }}\right)$ and the required energy for operating the pre-treatments [74]. The extra energy from the enhanced bio-methane production have been calculated as per the following equation 1[74]. On the basis of net energy estimation, enhanced bio-methane could cover the required energy for the thermal pretreatment at $80{ }^{\circ} \mathrm{C}$ for $1.5 \mathrm{~h}$ whereas negative net energy production was observed at $120{ }^{\circ} \mathrm{C}$ (fig.13C) [74].

Studies related to household waste and algal biomass thermal pre-treatment at $70{ }^{0} \mathrm{C}$ for $60 \mathrm{mins}$ and $8 \mathrm{~h}$ did not result in enhancement of biogas production [57],[75],[76]. Similarly negligible enhancement of biogas production was observed after thermal pre-treatment of sewage at $70{ }^{0} \mathrm{C}$ for 60 mins whereas production of biogas was improved by 20 times when a pre-treatment temperature was applied for $60 \mathrm{mins}$ at $90{ }^{0} \mathrm{C}$ [75]. Rafique et al. achieved a maximal enhancement of $78 \%$ higher biogas production with a methane content of $60 \%$ by pre-treatment at $70{ }^{0} \mathrm{C}$ [73]. Similarly, 30\% higher biogas yield was obtained with $69 \%$ methane content [62] and also $50 \%$ biogas volume was observed to increase with pre-treatment at $70{ }^{0} \mathrm{C}$ prior to thermophilic anaerobic digestion [77].

Net energy production:

$E_{\text {produced }}=E_{\text {Biomethane }} * V_{\text {Biomethane }} * \eta$

where:

$\mathrm{E}_{\text {Biomethane }}=$ energy content of biomethane $\left(6.5 \mathrm{KWh} / \mathrm{m}^{3}\right)$;

$\mathrm{V}_{\text {Biomethane }}=$ extra biomethane produced due to pretreatment $\left(\mathrm{m}^{3}\right)$;

$\eta=$ conversion factor ( 0.85 for thermal energy);

The total required energy for the thermal pretreatment is the sum of the required energy $\left(\mathrm{E}_{\text {Thermal }}\right)$ to obtain the desired pre-treatment temperature and the energy of the pretreatment chamber $\left(\mathrm{E}_{\text {Chamber }}\right)$ to maintain the heat :
$E_{\text {Thermal }}=C_{F W} * M_{F W} * \Delta T+C_{\text {Water }} * M_{\text {Water }} * \Delta T$

Where :

$\mathrm{C}_{\mathrm{FW}}=$ heat capacity of dry food waste $\left(1.92 \mathrm{KJ} \mathrm{Kg}^{-10} \mathrm{C}^{-1}\right)$; $\mathrm{M}_{\mathrm{FW}}=$ dry mass of food waste and/or TS (Kg/ton FW);

$\mathrm{C}_{\text {Water }}=$ heat capacity of water $\left(4.18 \mathrm{KJ} \mathrm{Kg}^{-10} \mathrm{C}^{-1}\right)$;

$\mathrm{M}_{\mathrm{Water}}=$ mass of water in $\mathrm{FW}(\mathrm{Kg} /$ ton $\mathrm{FW})$;

$\Delta T=$ temperature increase from room temperature to desired temperature $\left({ }^{0} \mathrm{C}\right)$

and $\Delta T^{*} A^{*}(k / s) * t$

\# (1) \& (2) adapted from [72].

where:

$A=$ total surface area of the pre-treatment chamber $\left(\mathrm{m}^{2}\right)$; $\mathrm{s}=$ thickness of the pre-treatment chamber wall (m);

$\mathrm{k}=$ heat conductivity of material used of pre-treatment chamber $\left(\mathrm{W} / \mathrm{m},{ }^{0} \mathrm{C}\right)$;

$\mathrm{t}=$ pre-treatment time (hours).

The density of FW varies between 0.3 and 1 ton $/ \mathrm{m}^{3}$ depending on its characteristics and composition [78]. Generally 1 ton $/ \mathrm{m}^{3}$ is taken for research work across the globe.

\subsection{Pyrolysis}

We use 'pyrolysis' as a general term for all processes whereby organic material is heated or partially combusted to produce secondary fuels and chemical products [222]. The input may be wood, biomass residues, municipal wastes etc. The products are gases, condensed vapors as liquids etc. Gasification is pyrolysis adapted to produce a maximum amount of secondary fuel gases. Pyrolysis is the basis of several methods that are being developed for producing fuel from biomass, which may include either crops grown for the purpose or biological waste products from other industries [219]. Crops studied as biomass feedstock for pyrolysis include native North American prairie grasses such as switchgrass and bred versions of other grasses such as Miscantheus giganteus. Crops and plant material wastes provide biomass feedstock on the basis of their lignocellulose portions. Many sources of organic matter can be used as feedstock for pyrolysis. Suitable plant material includes greenwaste, sawdust, waste wood, woody weeds; and agricultural sources including nut shells, straw, cotton trash, rice hulls, switch grass; and animal waste including poultry litter, dairy manure, and potentially other manures. Pyrolysis is used as a form of thermal treatment to reduce waste volumes of domestic refuse. Some industrial byproducts are also suitable feedstock including paper sludge and distillers grain [220]. Biomass is normally treated at temperatures higher than $300^{\circ} \mathrm{C}$ and the cellulose decomposes directly to gaseous products and residual char. Pyrolysis process is enhanced when carried out in presence of oxygen. At lower temperature the degradation rate is low and less volatile products are formed. The higher the temperature, more is the degree of degradation. A study reported $80-85 \%$ cellulose conversion to reducing sugars with more than $50 \%$ glucose by mild acid hydrolysis $(1 \mathrm{~N}$ $\mathrm{H}_{2} \mathrm{SO}_{4}, 97{ }^{0} \mathrm{C}, 2.5 \mathrm{~h}$ ) of pyrolysed product [81]. 
Aritra Das, Chanchal Mondal and Shyamal Roy/

Journal of Engineering Science and Technology Review 8 (5) (2015) 141-165

\subsection{Chemical pre-treatment}

Always during the anaerobic digestion process, there remains a possibility of increased organic acid accumulation after hydrolysis step, which may lead to process inhibition and failure of the anaerobic digestion process performances. Anaerobic digestion generally requires an adjustment of $\mathrm{pH}$ by increasing the alkalinity, so alkaline pre-treatment is preferred chemical pre-treatment [82]. Chemical pretreatment techniques are applied with the motive of destroying organic compounds by means of strong/weak acids, alkalis and oxidants [57]. Ozonation \& acidic pretreatments have been applied for biomass / wastes for enhancement of biogas production as well as to aid in efficient hydrolysis step [41]. This kind of pre-treatment method is highly dependant on the substrate characteristics. Chemical pre-treatment is suitable for higher lignin content substrates like leaves \& yard wastes. It is mostly not suitable for substrates that are rich in carbohydrates, due to accelerated degradation and loss of carbohydrates and excessive accumulation of volatile fatty acids [83].

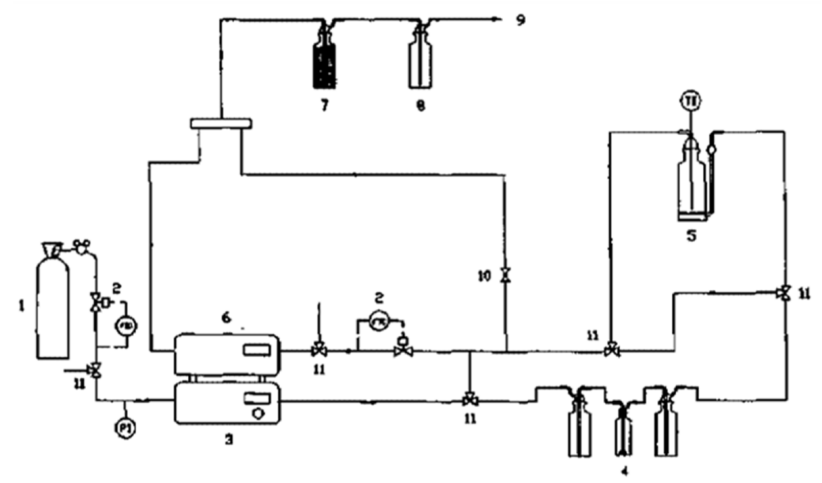

Fig14. Experimental ozonolysis setup: (1) oxygen cylinder, (2) automatic gas flow control valve, (3) ozone generator, (4) process gas humidifier, (5) reactor, (6) ozone UV spectrophotometer, (7) ozone catalytic destroyer, (8) iodide trap to test catalyst efficiency, (9) vent, (10) pressure regulation valve, (11) three-way valve [41].

\subsection{Ozonation}

There is no standard protocol and regulation for ozonation (fig. 14) pre-treatment of organic solid waste prior to anaerobic digestion. Ozone is a strong oxidant and decomposes itself to radicals and reacts both directly and indirectly with biomass/waste [84]. Direct reaction of ozone with biomass/waste is not fruitful; it leads to degradation of fermentable sugars thereby results in loss of bio-methane production [74]. Indirect reaction of ozone with biomass is all about the reaction with hydroxyl ions that causes degradation of complex organic compounds like lipids/fats, proteins thus resulting in sudden increase in bio-methane production [74]. A study reported the use of UV generator (model-Fischer) for ozonolysis. The device produced 0.6 mmol $\mathrm{O}_{3}$ with a flow rate of $35 \mathrm{~L} / \mathrm{h}$ using ambient air [74]. It is one of the way of removing lignin from biomass unlike other chemical pre-treatment methods, it doesnot produce any toxic products [41]. To reduce the potential ozone inhibition of anaerobic microbes, the pre-treatment vessel is always flushed with nitrogen gas after ozonation [74]. Moreover, ozonolysis reactions are carried out at normal room temperature and pressure [41] and ozone can be easily decomposed by catalytic bed or by increasing the temperature i.e., the processes can be designed to minimize environmental pollution [85]. Nevertheless, the drawback of ozonolysis is that a large amount of ozone gas is needed which is not very economic and increases the cost of the experiment [41]. Ozonolysis results in the increase of in vitro digestibility of the treated material. The degradation is limited mainly due to lignin, hemicellulose is slightly affected [41]. Ozone have been used to degrade lignin and hemicellulose in many lignocellulosic materials such as wheat straw [86], bagasse, green hay, peanut, pine [87], cotton straw [88] and poplar sawdust [89].

A study reported certain comparative results with ozonation pre-treatment and untreated wastes. The net methane yield of untreated $\mathrm{FW}$ was $440.3 \mathrm{mlCH}_{4} / \mathrm{gVS}$ [74]. Cumulative methane potential (CMP) curves of untreated and ozonated wastes are shown in figure $15 \mathrm{~A}$; the anaerobic digestion process was continued till 220 days long till complete degradation and bio-methanation was completely ceased [74]. All ozonated wastes produced less bio-methane as compared to the untreated substrate during the initial 15 days but thereafter higher yield of methane was obtained. The specific bio-methane potential (SBP) of 20 days is shown in fig 15B. The highest specific bio-methane potential enhancement of $9.2 \%$ was achieved with ozone dose of $0.068 \mathrm{gO}_{3} / \mathrm{gTS}$, followed by an increase of $7.8 \%$ with $0.034 \mathrm{gO}_{3} / \mathrm{gTS}$. Ozonation resulted in 22-46\% enhancement of cumulative bio-methane potential as shown in fig. $15 \mathrm{~A}$.

Another study reported $37 \%$ increase of cumulative methane potential from ozonated source separated organic fraction municipal solid wastes. During initial 20days of anaerobic digestion process the methane yield was maximum $\left(459.9 \mathrm{mlCH}_{4} / \mathrm{gVS}\right)$ for ozone dosage rate of $0.068 \mathrm{gO}_{3} / \mathrm{gTS}$, followed by $453.9 \mathrm{mlCH}_{4} / \mathrm{gVS}$ with 0.034 $\mathrm{gO}_{3} / \mathrm{gTS}, 447.6 \mathrm{mlCH}_{4} / \mathrm{gVS}$ with $0.101 \quad \mathrm{gO}_{3} / \mathrm{gTS}$ etc (fig.15B). Even though, for initial 20 days ozonation resulted in higher bio-methane yield compared to that of unteated wastes, the anaerobic digestion process can be lethal and inhibitory with high dosage rate of $0.202 \mathrm{gO}_{3} / \mathrm{gTS}$ [74]. It may be explained by the issue of chances of loss of fermentable sugars at higher concentration of ozone. Ozonation pre-treatment is not readily suitable to substrates with high carbohydrate content but can be attractive method of pre-treatment for recalcitrant and more complex organic biomass/waste.

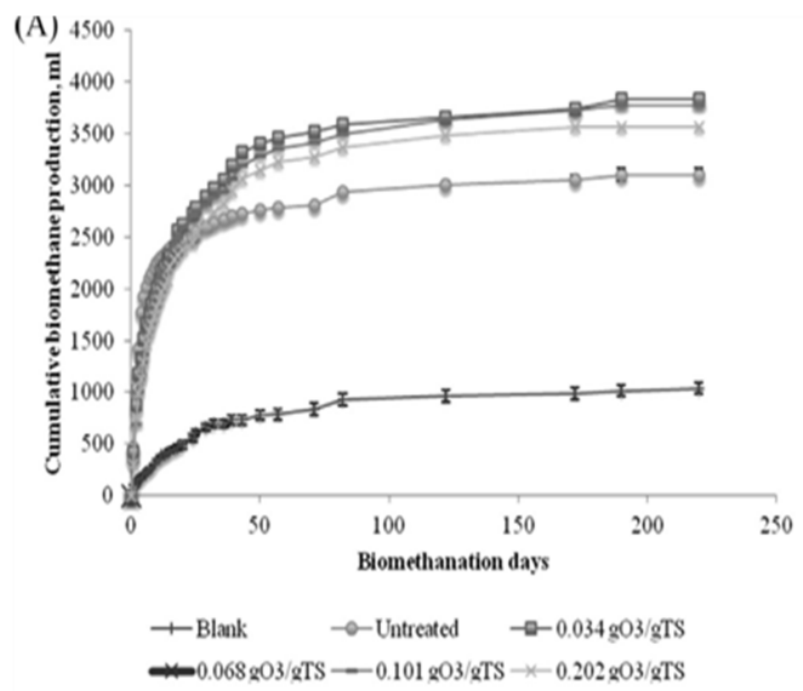


Aritra Das, Chanchal Mondal and Shyamal Roy/

Journal of Engineering Science and Technology Review 8 (5) (2015) 141-165

(B)

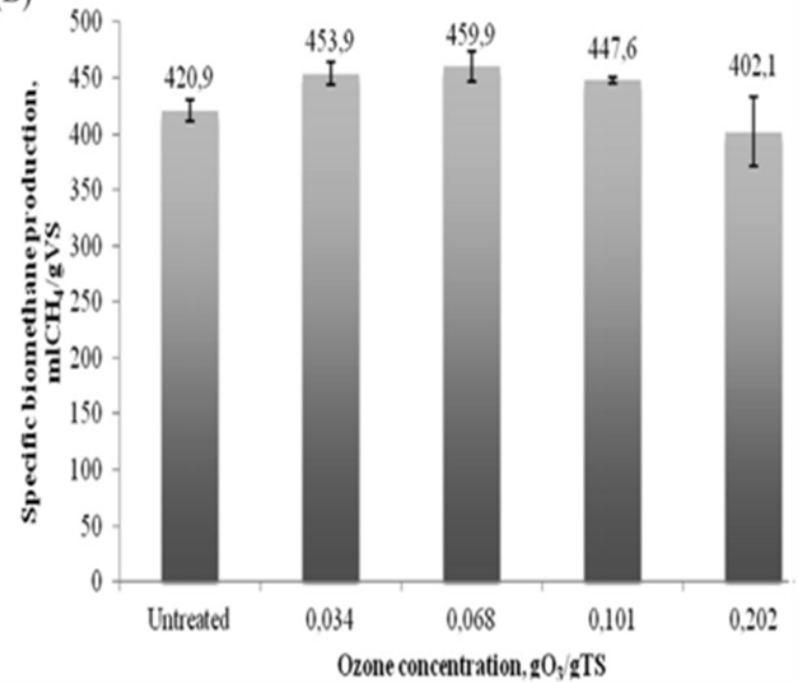

Fig 15. Effect of ozone on A) CMP curves; and B) SBP of FW during the initial 20 days [74]

\subsection{Alkaline pre-treatment}

Alkali or some bases can be readily used for the purpose of pre-treatment of lignocellulosic wastes [41]. Alkaline pretreatment can be carried out at ambient conditions and this is advantageous over other chemical methods but at the same time it is disadvantageous as the pre-treatment times are in the order of hours and days rather than minutes or seconds [41]. During alkaline pre-treatment, solvation and saponification occurs that induce the swelling of solids which increases the specific surface area of substrates and thereby more surface exposure becomes easy for the anaerobes [12],[67],[90],[91]. When biomass is pre-treated by alkali then the biomass itself consumes some of the alkali, so higher alkali reagents might be required for alkaline pre-treatment of biomass for desired anaerobic digestion enhancement in terms of excess bio-methane production [67]. COD solubilization is increased by saponification of uronic acids and acetyl esters as well as neutralization of various acids formed by the degradation of particulates [92]. Alkaline pre-treatment processes causes less sugar degradation and most of the salts can be regenerated or recovered [41]. Potassium, sodium, calcium and ammonium hydroxides have been used as alkaline pretreatment agents. Among all these, sodium hydroxide has been studied the most as pre-treatment agent of biomass/waste [93],[94],[95],[96]. In addition, to the effects of alkaline pretreatment the anaerobic digestion process might be affected by the accompanying cations present in these reagents including sodium, potassium, magnesium, calcium since the chemicals are added mostly as salts or hydroxides of these cations [57]. The inhibitory concentrations of these cations are very important to be considered for anaerobic digestion process stabilization. Kim et al., studied the inhibition of sodium ion concentration on thermophilic anaerobic digestion of food waste and reported that more than $5 \mathrm{~g} / \mathrm{L}$ of sodium resulted in lower biogas production ${ }^{97}$. Sodium is more toxic to propionic acid utilizing bacteria as compared to volatile fatty acid degrading bacteria [98]. Potassium ion is more toxic to thermophilic anaerobes as compared to mesophilic or psychrophilic anaerobes [100]. The inhibitory level of potassium begins at $400 \mathrm{mg} / \mathrm{L}$, though anaerobes are able to withstand upto $8 \mathrm{~g} / \mathrm{L}$ potassium [99]. Optimum concentrations of calcium and magnesium ions have been reported to be $200 \mathrm{mg} / \mathrm{L}$ and $720 \mathrm{mg} / \mathrm{L}$ respectively [100],[101]. Excess amounts of calcium can cause precipitation of carbonates and phosphates which results in scaling of reactors, pipes etc and reduces the process performance by hampering the specific methanogenic activity and results in loss of buffer capacity [102].

Anaerobic digestion process can be enhanced directly by the addition of trace elements like cobalt(Co), molybdenum $(\mathrm{Mo})$, selenium $(\mathrm{Se})$, iron $(\mathrm{Fe})$, tungsten $(\mathrm{W})$, copper $(\mathrm{Cu})$, aluminium (Al) and nickel (Ni) [57]. Fe, was found to be the most stable element for stabilization of anaerobic digestion process in a single-stage reactor treating food waste [103]. $45-65 \%$ higher methane production was obtained with supplement of trace metals like Co,Mo,Ni,Se and W [104]. But supplement of trace metals to biomass is never considered as pre-treatment method, rather it is considered as an effective method for obtaining higher biogas production rates with high methane content [57].

Slake lime or calcium hydroxide pre-treatment of lignocellulosic biomass resulted in effective yield of hydrolyzed product and it is easily possible to recover calcium from aqueous reaction systems as insoluble calcium carbonate by neutralizing it with less expensive carbon dioxide [41]. Further using the lime kiln technology, calcium hydroxide can be regenerated. The process of lime pretreatment is very simple; it comprises of slurrying the lime with water, spraying it onto the biomass and storing it in pile for a period of hours to weeks [41]. The particle size of the material is $10 \mathrm{~mm}$ or even less; elevated temperatures reduce contact time [41]. The enzymatic hydrolysis of lime pre-treated biomass is affected by structural features arising from the treatment, known as extents of acetylation, lignifications and crystallization [105]. Lime pretreatment (fig. 16) causes removal of amorphous substances (lignin and hemicellulose) from the lignocellulosic biomass and henceforth the crystallinity index is increased [41]. Lime has been used to pretreat wheat straw $\left(85{ }^{\circ} \mathrm{C}\right.$ for $\left.3 \mathrm{~h}\right)$ [106], poplar wood $\left(150{ }^{0} \mathrm{C}\right.$ for $6 \mathrm{~h}$ with $14 \mathrm{~atm}$ of oxygen) [107], switch-grass $\left(100{ }^{\circ} \mathrm{C}\right.$ for $\left.13 \mathrm{~h}\right)$ [108]. Pretreatment with slake lime (calcium hydroxide) increased the enzymatic hydrolysis of corn stover by a factor of 9 compared to that of untreated corn stover [41]. Pretreatment with lime can lead to corn stover polysaccharide conversions approaching 100\%. The optimal pretreatment conditions were determined to be a lime loading of $0.075 \mathrm{~g}$ of $\mathrm{Ca}(\mathrm{OH})_{2} / \mathrm{g}$ of dry biomass, a water loading of $5 \mathrm{~g} \mathrm{H}_{2} \mathrm{O} / \mathrm{g}$ of dry biomass and heating for $4 \mathrm{~h}$ at $120{ }^{\circ} \mathrm{C}$ [41].

Lignin removal increases enzyme effectiveness by removing the non-productive adsorption sites and by increasing access/exposure to cellulose and hemicellulose in the microfibrils [41]. Certain correlations between enzymatic digestibility and three structural features: (a) lignin content, (b) crystallinity, and (c) acetyl content have been reported by Chang et al [106]., that (1) extensive delignification is sufficient to obtain high digestibility regardless of crystallinity and acetyl content, (2) delignification and deacetylation removes parallel barriers to enzymatic hydrolysis and (3) crystallinity initially affects the rate of hydrolysis but has less effect on the final yield of hydrolysis product, i.e sugar. Therefore alkaline pretreatment plays an important role in exposing the cellulose enclosed within the microfibrils to enzymatic degradation. An effective pretreatment process should render the final lignin content in biomass to $10 \%$ or less after treatment [105]. Kim et al [105]., pretreated corn stover with excess 
Aritra Das, Chanchal Mondal and Shyamal Roy/

Journal of Engineering Science and Technology Review 8 (5) (2015) 141-165

slake lime $\left(0.5 \mathrm{~g}\right.$ of $\mathrm{Ca}(\mathrm{OH})_{2}$ of dry biomass $)$ at both nonoxidative $\left(\mathrm{N}_{2}\right)$ and oxidative $\left(\mathrm{O}_{2}\right)$ conditions at 25, 35, 45, and $55{ }^{0} \mathrm{C}$. Enzymatic digestibility of lime pretreated biomass is affected by the structural features of pretreatment and hence extensive delignification requires additional consumption of reagents (upto $0.17 \mathrm{~g}$ of $\mathrm{Ca}(\mathrm{OH})_{2} / \mathrm{g}$ of biomass) [41]. Delignification is highly dependant on temperature and presence of oxygen. Deacetylation requires a week's time to reach peak irrespective of non-oxidative and oxidative methods at $55{ }^{\circ} \mathrm{C}$. About $90 \%$ of acetyl was removed by both the methods at same temperature. The rate of enzymatic hydrolysis depends on enzyme adsorption. Kong et al [109]., reported that alkalis remove acetyl groups from hemicellulose (mainly xylan) therby reduce the hindrance of enzymatic hydrolysis and greatly influence carbohydrate digestibility. Sugar yield by enzymatic hydrolysis is related to acetyl group content.

Dilute $\mathrm{NaOH}$ treatment of lignocellulosic biomass causes swelling, increase in internal surface area, decrease in cellulose crystallinity, decrease in degree of polymerization, breakage of lignin structure and separation of structural linkages between carbohydrates and lignin [81]. A study reported increase in digestibility of $\mathrm{NaOH}$ treated hardwood from $14 \%$ to $55 \%$ with decrease of lignin content from $24-$ $55 \%$ to $20 \%$. No effect was observed for dilute $\mathrm{NaOH}$ treatment of softwoods with lignin content greater than $26 \%$ [43]. Especially dilute $\mathrm{NaOH}$ treatment is suitable for hydrolysis of low lignin content biomass; viz. straws (10$18 \%$ lignin content) [110]. Combined irradiation and 2\% $\mathrm{NaOH}$ has been applied for pretreatment of corn stalk, cassava bark and peanut husk [111]. Glucose yield of corn stalk was $20 \%$ in untreated samples compared to $43 \%$ after treatment with electron beam irradiation at a dose of $500 \mathrm{KGy}$ and $2 \% \mathrm{NaOH}$, but glucose yields of cassava bark and peanut husk were only $3.5 \%$ and $2.5 \%$ respectively. Lopez-Torres and Llorens [91] obtained a 11.5\% increased methane production with alkaline pretreatment of organic fraction municipal solid waste. Neves et al [112]., obtained $100 \%$ of the potential production with alkaline $(0.3 \mathrm{gNaOH} / \mathrm{gTS})$ pretreated barley waste. Patil et al [113]., studied the effect of alkaline pretreatment on water hyacinth, that possess less lignin content compared to other plants. They concluded that alkaline pretreatment had a smaller effect than mechanical pretreatments. So, alkaline pretreatment is not suitable for substrates with low lignin content.

Radio-frequency (RF) assisted alkaline pre-treatment $\left(0.1 \mathrm{~g} \mathrm{NaOH} / \mathrm{g}\right.$ of biomass loading ) at $90{ }^{\circ} \mathrm{C}$ resulted in high xylose yield from xylan than the conventional heating pretreatment [114],[115]. The optimum particle size and alkali loading were determined to be $0.25-0.50 \mathrm{~mm}$ and $0.25 \mathrm{~g}$ of $\mathrm{NaOH} / \mathrm{g}$ of biomass. Several studies have been conducted with switch-grass that comprises of $33.6 \%$ glucan, $19.3 \%$ xylan, $21.4 \%$ lignin and $3.9 \%$ ash. Glucose and xylose are the major sugars in switch-grass and yield of these sugars were used to estimate the efficiency of pre-treatment process. Sugar yield have been expressed as grams of sugar released per $100 \mathrm{~g}$ (dry weight) of original untreated switchgrass [41]. Microwave or conventional heating was adapted for switch-grass soaked in $\mathrm{NaOH}$ solutions of different concentrations [41]. With alkali loading of 0.05-0.3 g of alkali/g of biomass, microwave pretreatment resulted in higher sugar yields than conventional heating method [41]. Optimum concentration of $\mathrm{NaOH}$ for maximum yield of sugars is $0.1 \mathrm{~g} / \mathrm{g}$ of dry biomass. Microwave assisted alkaline pre-treatment is an efficient way to improve the enzymatic digestibility of the switch-grass [41].

Ammonia has also been used for pretreatment of lignocellulosic biomass to remove lignin. Iyer et al., described an ammonia percolation process (temperature: 170 ${ }^{0} \mathrm{C}$, ammonia concentration: $2.5-20 \%$, reaction time: $1 \mathrm{~h}$ ) for the pretreatment of a corn cobs/stover mixture and switch grass [41],[116]. The efficiency of delignification was 60 $80 \%$ for corn cobs and $65-85 \%$ for switch grass.

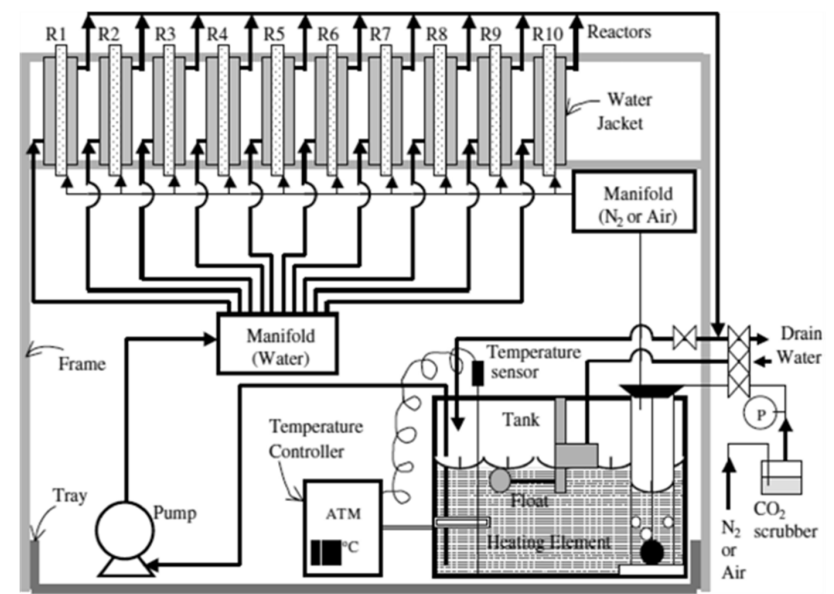

Fig. 16 Schematic diagram of the jacketed reactor system for lime pretreatment under non-oxidative $\left(\mathrm{N}_{2}\right.$ supply) and oxidative (air supply) conditions [41].

\subsection{Acidic pretreatment}

Both dilute and concentrated acid pretreatment have been studied for organic solid wastes like lignocellulosic wastes, food waste etc. Concentrated acids like $\mathrm{HCl}$ and $\mathrm{H}_{2} \mathrm{SO}_{4}$ have been used for pretreatment of lignocellulosic wastes [41]. Acidic pre-treatment have been effective for improving the rate of hydrolysis by solubilizing lignin and hemicelluloses but they are toxic, hazardous and corrosive in nature [41]. Corrosion-resistant reactors are needed for acidic pretreatment which makes the pre-treatment process very expensive and the acid should always be recovered for making the process economic [42],[117]. Xylan comprises of one-third of total carbohydrate content in many lignocellulosic wastes; hence achieving high xylan to xylose conversion is necessary to achieve favourable overall process economics [41]. Recently developed dilute $\mathrm{H}_{2} \mathrm{SO}_{4}$ pretreatment techniques use less severe conditions for conversion of xylan to xylose; dilute sulfuric acid pretreatment at concentrations below $4 \mathrm{wt} \%$ has been of great interest for studies by most researchers as it is very cost-effective and inexpensive [118],[119]. Furfural has been commercially manufactured from biomass using dilute sulfuric acid; the dilute acid hydrolyzes the hemicellulose to xylose and other sugars and further breaks down xylose to form furfural [23]. High temperature is favorable for dilute acid pretreatment and can help in achieving high reaction rates [120]. A study reported $100 \%$ conversion of cellulose to glucose after complete removal and recovery of hemicellulose as dissolved sugars after dilute acid pretreatment [23]. Other acids like nitric acid, phosphoric acid etc. has been tested against variable feedstocks. Crystallinity index, though not a function of pretreatment temperature, increased as a consequence of acid pretreatment of mixed hardwood [121]. This phenomena can be best explained as the removal of amorphous cellulose fraction and leaving behind the crystalline cellulose fraction. A study by Lu et al. 
Aritra Das, Chanchal Mondal and Shyamal Roy/

Journal of Engineering Science and Technology Review 8 (5) (2015) 141-165

reported upto $77 \%$ xylose yield whereas the glucose yield was only $8.4 \%$; the optimum conditions for corn stover pretreatment were a $\mathrm{H}_{2} \mathrm{SO}_{4}$ concentration of $2.0 \%$ and a reaction time of 43 minutes at $120{ }^{\circ} \mathrm{C}$ [122]. Another study involved subjection of corn stover to dilute $\mathrm{H}_{2} \mathrm{SO}_{4}$ pretreatment in a pilot scale vertical reactor with a residence time of $\sim 1 \mathrm{~min}$ at temperatures ranging from 180 to $200{ }^{\circ} \mathrm{C}$, solids loading between $25 \%$ and $35 \%(\mathrm{w} / \mathrm{w})$ and acid loadings of $0.03-0.06 \mathrm{~g}$ of acid/g of dry biomass [123]. All the pretreated samples showed higher pore volumes than untreated corn stover. Authors determined that porosity may be a factor for low digestibility but it is not a major factor for digestibility of lignocellulosic biomass [123].

Weak acid hydrolysis is one of the most effective pretreatment methods for lignocellulosic biomass. In general agreement with literatures there are two types of weak acid hydrolysis: (1) High temperature and continuous flow process $\left(\mathrm{T}>160{ }^{\circ} \mathrm{C}, 5-10 \mathrm{wt} \%\right.$ substrate concentration) [124],[125], (2) Low temperature and batch process for high solids loading ( $\mathrm{T}<=160{ }^{0} \mathrm{C}, 10-40 \%$ substrate concentrate) [120]. Mostly dilute sulfuric acid is sprayed onto raw material (biomass) at a temperature of $160-220{ }^{\circ} \mathrm{C}$ for a short period of time and held upto few minutes. The hemicelluloses are readily hydrolyzed into monomeric sugars with soluble oligomers from the cell wall matrix into the hydrolyzate. Hemicellulose removal increases porosity and improves hemicelluloses digestibility.

Hemicellulose is mostly amorphous in nature. Removal of this amorphous component increases the crystallinity index that affects the initial hydrolysis rates [121]. It has been observed that materials subjected to acid pretreatment / hydrolysis can be very difficult to ferment because of the presence of toxic substances [27]. $\mathrm{pH}$ neutralization is important for downstream processing that involves hydrolysis or fermentation. Dilute acid pretreatment have been reported to have negative impact on corn stover residues; spherical droplets have been found to form on the surface of corn stover. These droplets comprised of lignin carbohydrate complexes formed due to pretreatment under neutral and acidic $\mathrm{pH}$ at and above $300{ }^{\circ} \mathrm{C}$ [41],[125]. Acid pretreatment process is further costly than physico-chemical methods like AFEX, steam explosion and carbon dioxide explosion; acid pretreatment further involves the use of costly material of construction, high pressures, neutralization and conditioning of hydrolysate prior to biological steps, slow cellulose digestion by enzymes and non-productive binding of enzymes to lignin [41],[124].

\subsection{Liquid hot water}

Hot water at high temperature and pressure have been used to solubilize the components of biomass. Pretreatment with liquid hot water is occasionally used. For hot water pretreatment, size reduction of the biomass is not needed as the lignocelluloses particles break apart when cooked in water. Three types of liquid hot water configurations are used, namely concurrent, counter-current and flow-through. In concurrent pretreatment water and lignocellulose move in the same direction and the slurry of biomass and water is heated to the desired temperature and held at the pretreatment conditions for the desired residence time before being cooled. In counter-current pretreatment process, water and lignocellulose move in opposite direction through the pretreatment reactor. In a flow-through reactor, hot water is made to pass over a stationary bed of lignocelluloses. Water pretreatments use high pressure to maintain the water in the liquid state at elevated temperatures. The residence time for this process is usually $\sim 15$ mins at temperatures in the range of $200-230{ }^{0} \mathrm{C}$ [79]. All of the hemicelluloses is removed in the process, along with $4-22 \%$ of the cellulose, $35-60 \%$ of the lignin [79]. Other names of pretreatment with liquid hot water (LHW) are hydro-thermolysis, hydrothermal treatment, aqueous fractionation, solvolysis or aquasolv [23]. In the process of solvolysis, water is contacted with biomass for 15 minutes at a temperature of $200-300{ }^{0} \mathrm{C}$. Readily 40-60\% of the biomass is dissolved in the water. About $90 \%$ of the hemicelluloses is recovered as monomeric sugar when acid was used to hydrolyze the resulting liquid[79]. Acetic acid is formed in addition in the process that acts as catalyst for polysaccharide hydrolysis [79]. The monomeric sugars produced as a result of hydrolysis may further decompose to furfural (an inhibitory component of fermentation).

\section{Combined pretreatment methods}

\subsection{Thermo-chemical pretreatment.}

Different combinations of pretreatment methods have also been widely studied in order to improve the kinetics of anaerobic digestion process [126], [10]. Thermo-chemical pretreatment is one such coupled mechanism to treat biomass/waste for enhancement of biogas yield at faster rate i.e short duration of time. A study with anaerobic digestion of organic fraction municipal solid waste, pretreated by microwave heating (higher than $145^{\circ} \mathrm{C}$ ) coupled with alkaline treatment, resulted in release of more amount of refractory material per gCOD; the amount of biogas obtained was very low [127]. A very similar incident was observed with pig manure pretreated with lime and heated to temperatures above $110^{\circ} \mathrm{C}$ [73],[128]. Due to chemical pretreatment, excess hydrolyzed product of proteins and carbohydrates were formed namely amino acids and sugars that reacted among each other and resulted in formation of melanoidins. But alkaline pretreatment combined with low temperature heating $\left(70^{\circ} \mathrm{C}\right)$ resulted in $78 \%$ increase in biogas production with $60 \%$ methane content as compared to $28 \%$ increase in biogas production with $50 \%$ methane content obtained by thermal pretreatment at higher temperatures $\left(>100{ }^{\circ} \mathrm{C}\right)[73]$.

\subsection{Thermo-mechanical pretreatment}

Mechanical pretreatments including maceration, sonication, milling, grinding/crushing have been studied together with thermal pretreatment techniques [57]. Initially mechanical pretreatment mostly helps in reducing the particle size of biomass and readily helps in easy volume reduction and better means of biomass handling and storage. This combination of pretreatment is not common for organic fraction municipal solid wastes and have been less studied [57]. A study by Zhang et al. reported highest enhancement of biogas production (17\%) by grinding rice straw upto $10 \mathrm{~mm}$ and further heating to $110{ }^{\circ} \mathrm{C}$ [47]. One disadvantage reported was the increased concentration (64\%) of ammonia in the reactor due to excess protein hydrolysis; which may lead to anaerobic digestion process instability due to microbial inhibition [129]. Another study reported 70\% higher biogas yield within a period of 5 days with temperature and pressure catalyzed $\left(160-200^{\circ} \mathrm{C}\right.$ at 40 bar for 60 minutes) pretreatment prior anaerobic digestion [130]. Wett et al. studied the disintegration of sewage sludge pretreated at $19-21$ bar pressure and $160-180{ }^{\circ} \mathrm{C}$ for $1 \mathrm{~h}$ 
[129]. The combined pretreatment resulted in a $75 \%$ increased biogas production, dewatering characteristics of the sludge also improved and the disposal cost was minimized by $25 \%$.

\subsection{Hydro-thermal pretreatment}

Hydrothermal pretreatment of lignocellulosic biomass for enhanced bio-ethanol and biogas production is gaining high importance in the $21^{\text {st }}$ century [131]. Water under high pressure and temperature can penetrate into the biomass, hydrate cellulose and remove hemicellulose and part of lignin [41]. The major advantages of hydrothermal pretreatment are no addition of chemicals and no requirement of corrosion resistant materials for hydrolysis reactors in the process. Physical treatment involving maceration, milling/or grinding is a very cost-effective process. Hence, particle size reduction of biomass may be avoided in hydrothermal pretreatment and requires very less amount of chemicals for neutralization of the hydrolyzate [131]. But certain disadvantages associated with the hydrothermal process are energy requirements of hydrothermal process, longer residence time may lead to charring of biomass, decreases $\mathrm{pH}$ of biomass slurry due to hydrothermal oxidation of sulfur and phosphorus in biomass which further results into production of inorganic acids. The methanogens perform well in the $\mathrm{pH}$ range of 6.8-7.2. Hence addition of a significant amount of alkali to the process reduces the risk of acid inhibition. Nevertheless, cation concentration of above $1500 \mathrm{mg} / \mathrm{L}$ exhibits toxicity. So, careful addition of alkali to process should be done depending upon the inhibitory level for the process. Hydrothermal pretreatment followed by addition of appropriate $\mathrm{NaOH}$ is potentially effective for lignocellulosic biomass (rice husk and rice straw). Hydrothermal pretreatment of rice straw for $10 \mathrm{mins}$ at $200{ }^{\circ} \mathrm{C}$ followed by alkali addition of $5 \% \mathrm{NaOH}$ reported biogas and methane yields of $315.9 \mathrm{~L} / \mathrm{Kg} \mathrm{VS}$ and $132.7 \mathrm{~L} / \mathrm{Kg}$ VS respectively. This method has been widely studied for treating biomass including cow manure, pig manure, fruit \& vegetable waste, food waste and municipal sewage sludge. Hydrothermal pretreatment has been used in municipal sewage sludge digestion in industrial operation [131]. With hydrothermal pretreatment, the municipal sewage sludge was dissolved into liquid phase that skips the slow biological enzyme hydrolysis [131]. The first hydrothermal treatment plant was developed in the year 2002 [132]. In 2008, another hydrothermal equipment was built in a municipal wastewater treatment plant [133]. At 1978, Huang used hydrothermal process to improve sludge digestion biogas production. Study reported that heating sludge at $175{ }^{0} \mathrm{C}$ could increase biogas production by 60 - $70 \%$ [134]. Another study by $\mathrm{Li}$ and Noikeal evaluated hydrothermal effect at different temperature and heating time [135]. Hydrothermal pretreatment of lignocellulosic materials have been less studied. For hydrothermal pretreatment, with organic matters dissolving and hydrolyzing, parts of solid organic matters are liquefied as a form of low molecular weight organic matter. Under hydro-thermal pretreatment, biomass / waste would release organic carbon into liquid phase [131]. The procedure of biochemical methane potential test for different biomass waste is depicted in fig 17.

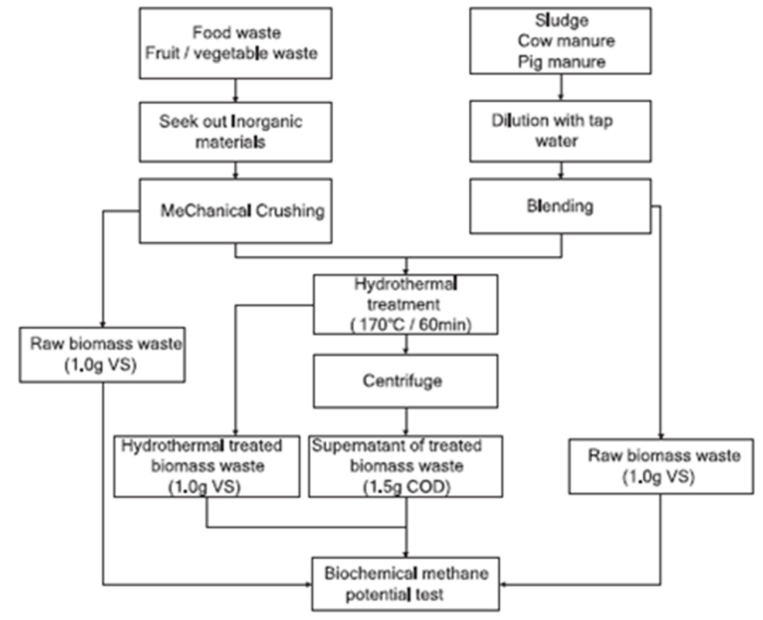

Fig. 17 Procedure of BMP test [131]

A detailed study reported use of cow manure, pig manure, municipal sewage sludge, food waste and fruit $\&$ vegetable waste as feedstocks for anaerobic digestion process with prior hydrothermal treatment [131]. Cow and pig manure were collected from two breed plants in a suburban district in Beijing city [131]. Municipal sewage sludge (MSS) was sampled from the Beixiaohe municipal wastewater treatment plant. Fruit \& vegetable waste was taken from a farmers market in Beijing city, where fruit \& vegetable waste was centrally collected [131]. Food waste was collected from student canteen in Tsinghua University [131]. The sampled food waste was a mixture of lunch and supper residues [131]. The biochemical methane potential test of raw and treated cow manure show that after $170{ }^{\circ} \mathrm{C} / 1 \mathrm{~h}$ hydrothermal pretreatment, the cumulative biogas production increased from 210 to $238 \mathrm{~mL} / \mathrm{g}$ VS (fig 18A) [131]. After 14days anaerobic digestion, the biogas volume curve became smooth indicating that all the biodegradable solids have been completely digested [131]. The daily biogas yield, show that peak occurred on first day for all samples (supernatant, raw cow manure, treated cow manure) (fig 19A). Hydrothermal pretreatment was not very effective for cow manure as the yield of methane in obtained biogas was less, i.e; the methane yield did not increase after hydrothermal treatment, rather decreased by $6.9 \%$ [131]. Protein content of cow manure is the least among all other biomass samples [131]. The biogas production of pig manure increased by $7.8 \%$ after hydrothermal treatment [131]. Compositional analysis of biogas have been done. Methane yield have been enhanced by $14.6 \%$ from 253.8 to $290.8 \mathrm{~mL} / \mathrm{g}$ VS after hydrothermal pretreatment (fig 18B). The digestion degree of tested samples of pig manure was high compared to that of cow manure which can be explained by the higher content of proteins and lipids in pig manure [131]. 

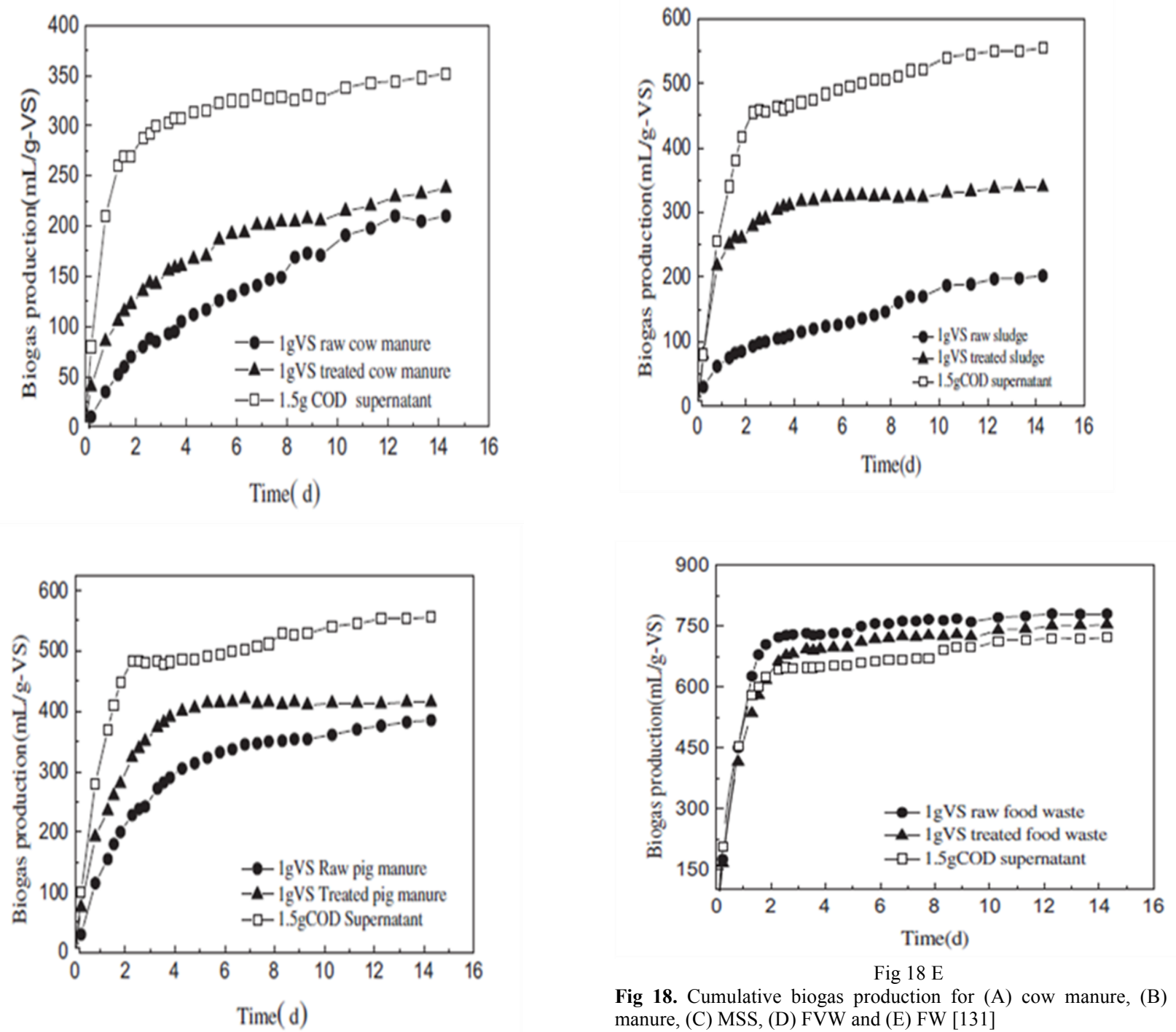

Fig $18 \mathrm{E}$

Fig 18. Cumulative biogas production for (A) cow manure, (B) pig manure, (C) MSS, (D) FVW and (E) FW [131]

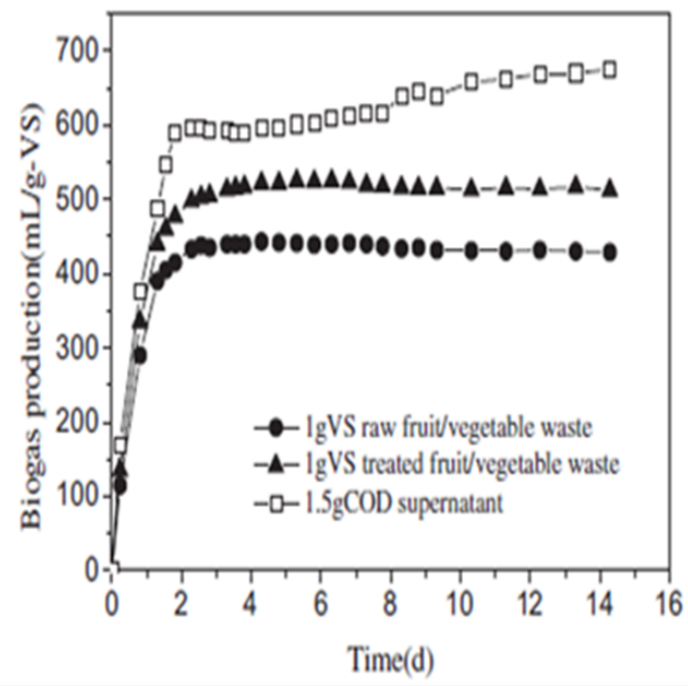

Hydrothermal pretreatment have been highly successful for municipal sewage sludge, this can be explained as the cellular degradation of municipal sewage sludge due to heat treatment releasing soluble organic substances resulting in higher biogas yield [131]. The ultimate biogas yield increased by $67.8 \%$ from 202 to $339 \mathrm{~mL} / \mathrm{g} \mathrm{VS}$ (fig $18 \mathrm{C}$ ). Peak productions ended within first three days of biochemical methane potential test/anaerobic digestion process [131]. Highest peak was obtained on the first day of the process; $175 \mathrm{ml}$ for supernatant, $137 \mathrm{~mL}$ for the treated sample, $32 \mathrm{~mL}$ for the raw sample (fig 19B). Methane content of biogas increased by $65.5 \%$ [131]. The lipid and protein content are relatively high compared to that of other wastes [131].

The biochemical methane potential test of fruit \& vegetable wastes led to the increase in cumulative biogas production by $18.5 \%$ from 443 to $525 \mathrm{~mL} / \mathrm{g}$ VS for raw waste after the hydrothermal pretreatment (fig 18D). A little amount of biogas have been observed to evolve during the last few days showing that hydrothermal pretreatment have less impact on the digestion time of fruit $\&$ vegetable wastes [131]. The daily biogas yield was highest for the supernatant followed by treated sample and untreated sample (fig 19C). Methane content increased by $16.1 \%$ from 280.9 to 326 $\mathrm{mL} / \mathrm{g}$ VS after heating fruit \& vegetable wastes [131]. Protein and lipid content of fruit \& vegetable wastes was at a 
Aritra Das, Chanchal Mondal and Shyamal Roy/

Journal of Engineering Science and Technology Review 8 (5) (2015) 141-165

medium level as compared to other wastes [131]. Among all the wastes, crude fiber content was maximum in fruit \& vegetable wastes[131]. Biodegradable volatile solids were higher than refractory volatile solids in crude fibers [131].

Ultimate biogas production decreased by $3.5 \%$ for food waste (fig 18E). Hydrothermal pretreatment had very less impact on the digestion time as methane production was completed within the first two days of the biochemical methane potential test process [131]. The highest daily biogas yield was $275 \mathrm{~mL}$ for the raw sample and $250 \mathrm{~mL}$ for treated sample (fig 19D). The digestion degree of the tested food waste samples was high but the efficiency of the anaerobic digestion did not improve with hydrothermal treatment; the methane production decreased by $6.9 \%$ after treatment. High methane content of food waste can be correlated to the presence of more lipid and protein. Lipid content of waste was 2-50 times higher than that of the other materials [131].

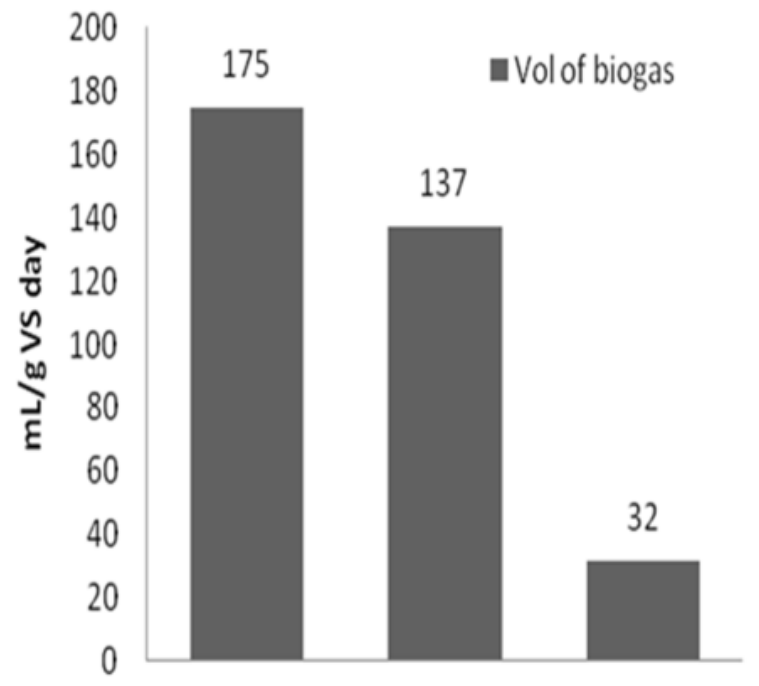

Supernatent Treated MSS Raw MSS

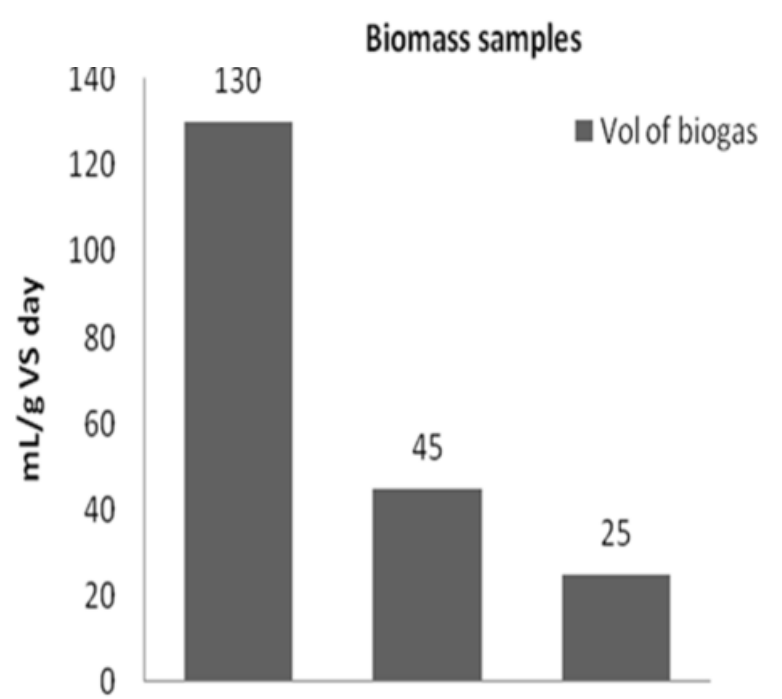

Supernatent Cow manure Treated cow manure

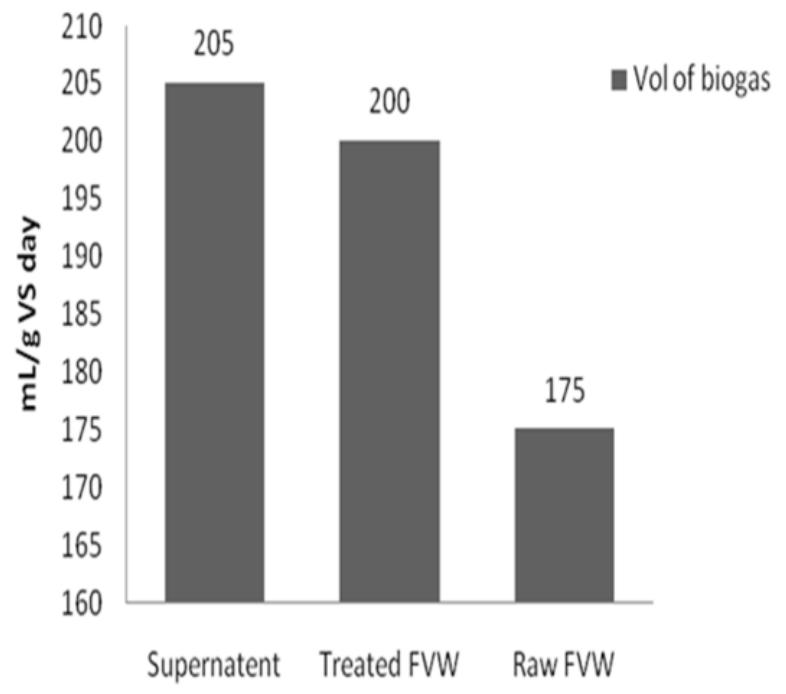

Biomass samples

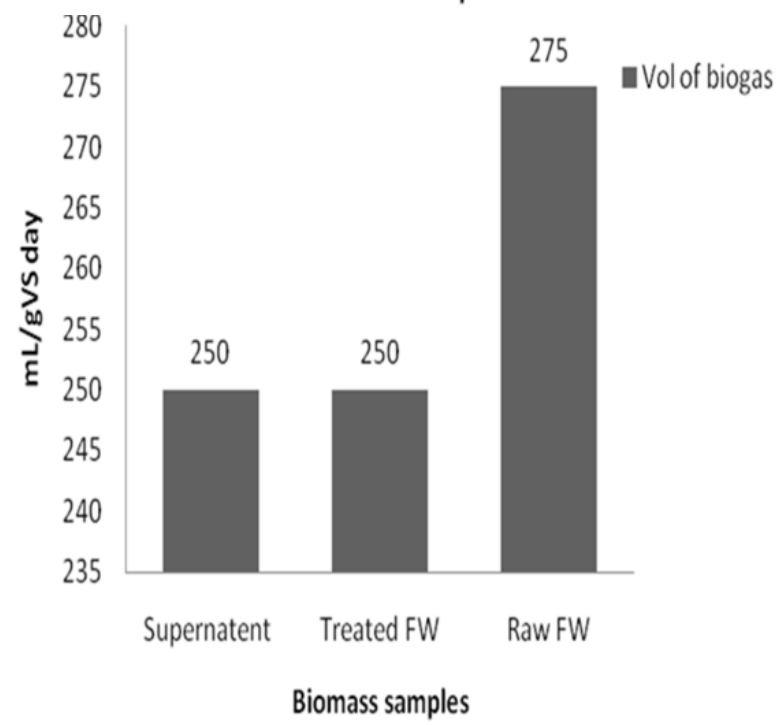

Fig. 19 Yield of biogas for (A) Cow manure, (B) MSS, (C) FVW and (D) FW during the first day of AD process [131]

\subsection{Steam explosion}

This pretreatment method have been studied to open up plant fibers and remove biomass recalcitrance (resistance to chemical and enzymatic degradation by microbial consortium) [224]. So, steam explosion is one such method that makes the biopolymer available for subsequent processes, i.e fermentation, hydrolysis and densification processes [224]. Biomass such as wood are composite materials of high mechanical strength [225]. The major components are cellulose embedded in a matrix of lignin and hemicelluloses [225]. Lignin, hemicellulose and cellulose altogether form fiber bundles and are the base for biomass tissues such as wood. Their natural function is to bear mechanical load.

Steam explosion have been discussed as a pretreatment process for the production of solid biofuel pellets to increase the calorific value and pelletizing properties of biomass [224]. In this method, the biomass is subjected to a sudden explosive decompression (biomass is treated with high pressure saturated steam \& suddenly the pressure is reduced) [224]. Steam explosion is typically initiated at a temperature 
Aritra Das, Chanchal Mondal and Shyamal Roy/

Journal of Engineering Science and Technology Review 8 (5) (2015) 141-165

of $160-260{ }^{\circ} \mathrm{C}, 0.69-4.83 \mathrm{MPa}$ for several seconds to a few minutes before the material is exposed to atmospheric pressure [42]. The mixture of steam and biomass is held for a period of time to promote hemicellulose hydrolysis and the process is terminated by a thermal decompression [41].

Steam explosion have been studied for lignocellulosic biomass like wood. Steam explosion is recognized as one of the most cost-effective pretreatment process for hardwoods and agricultural residues but it is less effective for softwoods [42]. One such process describes that wood chips have been fed from a bin through a screw loading valve in a masonite gun. The chips have been steam heated to $285{ }^{\circ} \mathrm{C}$ for 2 mins at a pressure of $3.5 \mathrm{MPa}$ [224]. The pressure have been rapidly increased to about $7 \mathrm{MPa}(70$ bar $)$ for about 5 seconds followed by discharging the chips through restricted orifices and exploded at atmospheric pressure to a pulp [224]. The process causes lignin transformation due to very high temperature thereby increasing the potential of cellulose hydrolysis [41]. During steam explosion organic acids like acetic acid and others are formed [136]. Hemicellulose is expected to be hydrolyzed by the produced organic acids [136]. Acetic acid is released from the wood that causes partial hydrolysis of cell wall components [136]. Use of dilute acids like sulfuric or nitric can accelerate the process, i.e result in higher hydrolysis rates of the hemicelluloses [137],[138],[139]. According to Garrote et al., the general advantages of using steam explosion over other pretreatment methods are: (1) No chemicals/reagents are used except water, (2) Good yield of hemicellulose with lesser degraded by-products, (3) Corrosion of equipment is minimum due to mild $\mathrm{pH}$ of the process, (4) Stages of acid handling and recycling are avoided [140]. The conventional mechanical maceration requires $70 \%$ more energy than steam explosion to achieve the same particle size reduction. Nevertheless, steam explosion with addition of suitable catalyst have been less studied but have been claimed to be closest to commercialization.

The method of steam explosion have been studied for environment friendly pulping process [141], as pre-treatment for microbial bioethanol or biogas production [142],[143]. The method have also been studied as a pretreatment measure for increasing heating value, bonding properties and hydrophobicity of the wood [144],[145]. During steam explosion the lignin is softened, released and gets uniformly distributed over the raw material. A study reported $90 \%$ efficiency of enzymatic hydrolysis obtained in $24 \mathrm{~h}$ after steam explosion of poplar chips compared to only $15 \%$ hydrolysis yield of untreated chips [146]. Lignin have been removed by steam explosion, only upto a certain extent [147]. The lignin melts and gets redistributed over the materials as a result of depolymerization reactions [147]. The removal of lignin and hemicellulose increases the volume of the treated sample and the sample becomes much more porous that makes easy route for further hydrolysis by enzymes or acid [41]. The factors that affect steam explosion pretreatment method are residence time, temperature, chip size and moisture content [148],[149]. The optimum conditions for hemicellulose solubilization may be $270{ }^{0} \mathrm{C}$ for $1 \mathrm{~min}$ (higher temperature, lesser residence time) or $190^{\circ} \mathrm{C}$ for $10 \mathrm{~min}$ (lower temperature, longer residence time)[148]. Water acts as acid at high temperature [150],[151],[152]. A little addition of $\mathrm{H}_{2} \mathrm{SO}_{4}\left(\right.$ or $\left.\mathrm{SO}_{2}\right)$ or $\mathrm{CO}_{2}$ $[0.3-3 \%$ w/w] in steam explosion can decrease the production of inhibitory compounds, lead to complete removal of hemicellulose and improve the efficiency of hydrolysis [153],[154]. A study by Kobayashi et al reported improvement of fermentation process for the conversion of bamboo to methane [155]. Steam exploded bamboo resulted in enhanced production of methane (maximum methane production achieved was $215 \mathrm{~mL}$ from $1 \mathrm{~g}$ bamboo sample) with $3.53 \mathrm{M}$ Pa pressure and application for 5 mins [155].

Certain limitations associated with the steam explosion method are: (1) incomplete disruption of fibers, (2) generation of inhibitory components to microbial growth, enzymatic hydrolysis and fermentation [156]. As inhibitory degradation products are formed pretreated biomass needs to be washed with water to remove the inhibitory materials along with water soluble hemicelluloses [157]. The major role of hemicellulose in the wood is to impart viscoelastic properties [157]. Especially wood becomes brittle and rigid upon removal of hemicelluloses from it. The removal of hydroxyl $(-\mathrm{OH})$ groups makes the surface more hydrophobic[157]. Cellulose and lignin are also affected by steam explosion conditions. The apparent increase of lignin content during heat treatment have been observed due to hemicelluloses degradation product, furfural and lignin polymerization [157].

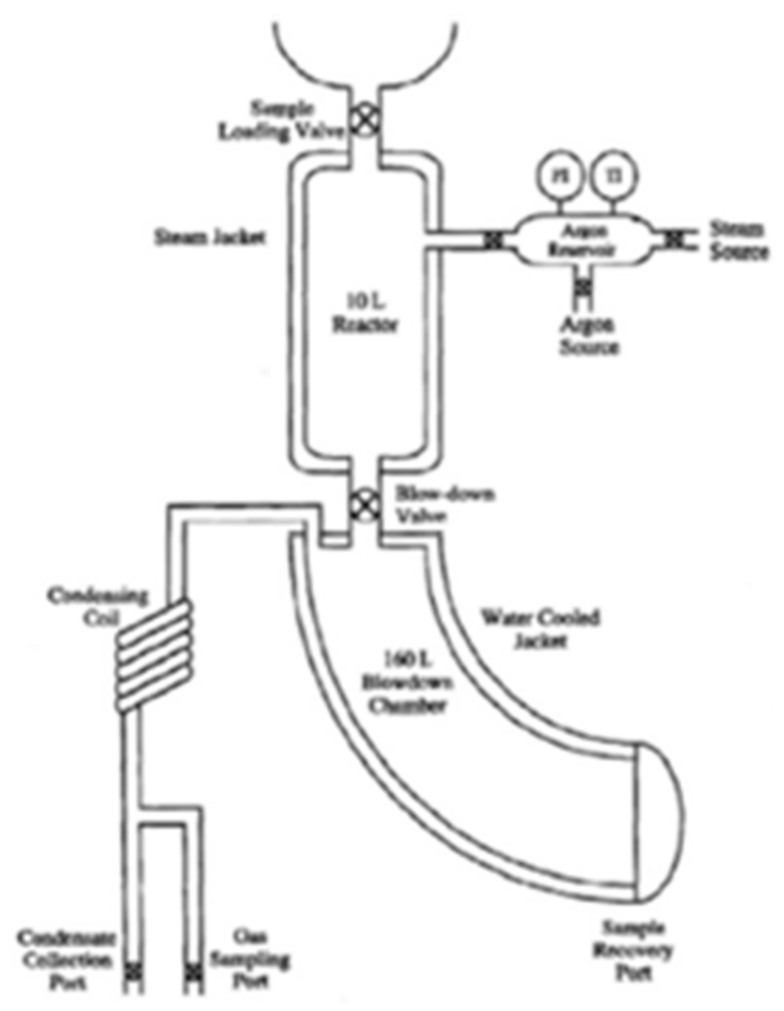

Fig. 20 Batch steam explosion reactor [170]

\subsection{Carbon dioxide explosion}

This method of pretreatment is based upon supercritical fluid explosion of lignocellulosic materials [158]. Supercritical $\mathrm{CO}_{2}$ is characterized by "gas-like" mass transfer and "liquidlike" solvating power, that makes it easier to permeate into the micro pores of lignocelluloses [158],[159]. Factors affecting the efficiency of the supercritical $\mathrm{CO}_{2}$ pretreatment process are: (1) pretreatment temperature, (2) moisture content of biomass, (3) pretreatment time and (4) pretreatment pressure [159], [160], [161], [162],[163],[164], [165],[166],[167],[168],[169]. Pretreatment temperature contributes to supercritical $\mathrm{CO}_{2}$ in many ways. On one hand 
Aritra Das, Chanchal Mondal and Shyamal Roy/

Journal of Engineering Science and Technology Review 8 (5) (2015) 141-165

higher temperature have been benefitial to mass transfer, softening of lignin and degradation of hemicelluloses, which could greatly enhance the final explosion [171],[172],[173]. Similarly, on the other hand temperature could also affect the properties of supercritical $\mathrm{CO}_{2}$ pretreatment including density, diffusion coefficient of $\mathrm{CO}_{2}$ and solubility of water in supercritical $\mathrm{CO}_{2}$ [158]. This method is less expensive i.e, cost-effective compared to that of steam explosion and ammonia treatment methods [41],[158]. Supercritical fluid refers to a fluid that is in gaseous form but it is compressed at a temperature above the critical point to a liquid like density [41]. However, the energy requirements of carbon dioxide explosion is less as compared to that of steam explosion [41]. $\mathrm{CO}_{2}$ dissolves in water to form carbonic acid and the formed organic acid promotes the rate of hydrolysis [41]. Supercritical $\mathrm{CO}_{2}$ have been studied by researchers to able to penetrate the rigid structure of biomass [41]. $\mathrm{CO}_{2}$ have been suggested to hydrolyze both hemicellulose and cellulose but low temperature prevents appreciable decomposition of monosaccharides by the acid [41],[158]. Upon explosive release of $\mathrm{CO}_{2}$ pressure, the microfibrils are disrupted that offers higher exposure of surface area of the substrate to hydrolysis [41]. A study reported pretreatment of alfalfa by $\mathrm{CO}_{2}$ explosion method and $75 \%$ of the theoretical glucose have been released during $24 \mathrm{~h}$ of the enzymatic hydrolysis [174]. Compared to steam explosion and ammonia treatment methods, the yield was low but the yield was comparatively higher than the untreated wastes. Zheng et al found that $\mathrm{CO}_{2}$ explosion was much more costeffective compared to that of steam explosion and ammonia pretreatment methods [175]. Moreover, $\mathrm{CO}_{2}$ explosion method didn't cause formation of inhibitory products. Increased pressure initiated the penetration of $\mathrm{CO}_{2}$ molecules into the crystalline structure and thereby produced more glucose upon hydrolysis. As compared to steam explosion method, $\mathrm{CO}_{2}$ explosion is operated at lower temperatures hence the monomeric sugars are not degraded [41].

Effect of pretreatment temperature and pretreatment time have been studied for three individual biomass namely corn cob, corn stalk and rice straw [158]. The raw materials bearing $50 \%$ moisture content have been pretreated at $15 \mathrm{MPa}$ pressure and various temperatures ranging from $50-$ $160{ }^{0} \mathrm{C}$ for 30 mins respectively [158]. The outcomes of pretreatment process were affected by temperature [158]. Yield of reducing sugar increased with increase in temperature upto $100{ }^{\circ} \mathrm{C}$ and further decreased with the increasing temperature after $100{ }^{0} \mathrm{C}[158]$. Moreover, the samples pretreated at $100{ }^{\circ} \mathrm{C}$ resulted in $13.35 \%, 5.47 \%$ and $5.68 \%$ increase in sugar yields for corn cob, rice straw \& corn-stalk[158].

The effect of moisture content have been also estimated for the above mentioned lignocellulosic feedstocks [158]. Experiments have been conducted at $15 \mathrm{MPa}$ and $100{ }^{\circ} \mathrm{C}$ for 30 mins [158]. The biomass had a variable moisture content in the range of $0-75 \%$ [158]. Maximum yield of reducing sugar was obtained at $50 \%$ moisture content [158]. The yield of reducing sugar increased with increasing moisture content upto $50 \%$ but further yield of sugar decreased with moisture content higher than that of 50\% [158]. The highest reducing sugar yields obtained with $50 \%$ moisture content of biomass were $39.15 \%, 27.97 \%$ and $36.60 \%$ respectively for corn cob, corn stalk and rice straw [158]. The biomass samples with low moisture content, did not show any significant difference in yields of reducing sugar as compared to that of untreated wastes [158]. Supercritical $\mathrm{CO}_{2}$ is non-polar in nature and have weak interactions with the strong hydrogen bonds of lignocelluloses especially at low temperature (below $200{ }^{\circ} \mathrm{C}$ ) [158]. Water acts as a polar molecule that breaks hydrogen bonds of the cellulose under supercritical $\mathrm{CO}_{2}$ conditions [158]. Three possible effects of water on supercritical $\mathrm{CO}_{2}$ pretreatment may be swelling of microfibrils, hemicellulose hydrolysis assisted by carbonic acid and cooking effect of saturated steam / vapor pressure [158]. More precisely, the water molecules cause swelling of the fibers and makes easier and deeper $\mathrm{CO}_{2}$ penetration into the biomass [158].

\subsection{Ammonia fiber explosion (AFEX)}

In agreement with literature of researchers across the globe, AFEX is carried out in liquid ammonia that readily removes considerable amount of lignin and hemicellulose from the biomass and further leads to decrystallization of cellulose (lignin solubilization, hemicelluloses hydrolysis, cellulose decrystallization) [23],[41]. Certain distinctive features of AFEX pretreatment process are: (1)Ammonia can be recovered and reused from the process; remaining ammonia in biomass serves as nitrogen source for the microbes in downstream processing [174]; (2) AFEX treated biomass remains stable for longer periods of time and ammonia recovery is $100 \%$. Ammonia recovery is a dry to dry process [176]; (3) No degradation of cellulose and hemicelluloses [176],[41]; (4) AFEX pretreated biomass are not required to be neutralized prior enzymatic hydrolysis [176]; (5) Clean sugar streams are produced upon enzymatic hydrolysis of AFEX treated biomass [176]. In comparison to other pretreatment methods, AFEX is not cost-effective [41]. The cost of ammonia and ammonia recovery drives the cost of AFEX pretreatment techniques [41]. Like other pretreatment techniques, AFEX is also dependant on certain parameters whose optimum values are really important for maximum throughput of the pretreatment process.

Ammonia loading, residence time, moisture content and temperature are important for AFEX treatment to be successful [176]. Essentially AFEX is very similar to steam explosion process but the difference lies in implementing ammonia to the pretreatment process [41]. A typical AFEX process involves the use of liquid ammonia at the rate of 1-2 $\mathrm{Kg} / \mathrm{Kg}$ of dry biomass at $90{ }^{0} \mathrm{C}$ for 30 mins [41]. Lignocellulosic materials like corn stover, wheat straw, wheat chaff etc has been pretreated with AFEX process. The biomass is subjected to liquid ammonia at high pressure and temperature for a considerable period of time and then suddenly the pressure is reduced to provide a thermal decompression [41]. Liquid anhydrous ammonia have been used for AFEX process of corn stover [41],[176]. The process can be carried out in the temperature range of 60 $100{ }^{0} \mathrm{C}$ and $250-300$ psi pressure for 5 mins [176]. A study reported 2.3 times increase in ethanol yield from AFEXtreated corn stover over that of untreated sample [177]. Optimal conditions of AFEX pretreatment of corn stover have been reported to be $90{ }^{0} \mathrm{C}$ temperature, $1 \mathrm{Kg}$ ammonia per $\mathrm{Kg}$ of dry biomass loading, $60 \%$ moisture content(dry weight basis), $5 \mathrm{mins}$ residence time (holding at target temperature) [41],[177].

Despite of enhancement or aid in enzymatic hydrolysis of AFEX-treated biomass, the method was not very effective for biomass with higher lignin content (newspaper and aspen chips [156]. Hydrolysis yield of AFEX-pretreated newspaper and aspen chips have been reported to be $40 \%$ and below $50 \%$ respectively [156]. During the AFEX 
Aritra Das, Chanchal Mondal and Shyamal Roy/

Journal of Engineering Science and Technology Review 8 (5) (2015) 141-165

treatment process, only a small portion of solid have been observed to solubilize which indicated that hemicellulose doesnot readily dissolves in liquid ammonia [41]. The structure of the treated material gets altered and have been observed to indicate increase in water holding capacity and higher digestibility [27], further enzymatic hydrolysis resulted in $90 \%$ hydrolysis of cellulose and hemicellulose especially with Bermuda grass (5\% lignin) and bagasse (15\% lignin)[178]. Switch grass have also been tested by AFEX pretreatment [179]. Optimal AFEX treatment conditions are $100{ }^{\circ} \mathrm{C}$, an ammonia loading of $1 \mathrm{Kg}$ ammonia/Kg of dry biomass, moisture content of $80 \%$ (dry weight basis) and residence time of 5mins [179]. Ethanol yield have been reported to be 2.5 times higher compared to that of untreated sample [179]. Similar study by Lee et al reported removal of 50\% lignin from corn stover with a loading og $12 \mathrm{~mL} / \mathrm{g}$ of ground corn stover in 4 days [180]. Pretreatment temperature is an important parameter for AFEX process. The pretreatment temperature determines the amount of ammonia vaporized during the explosion phenomena and influences system pressure [41],[176]. Higher temperature causes more ammonia vapors to flash the biomass thereby greater disruption of fiber structure occurs [41],[176].
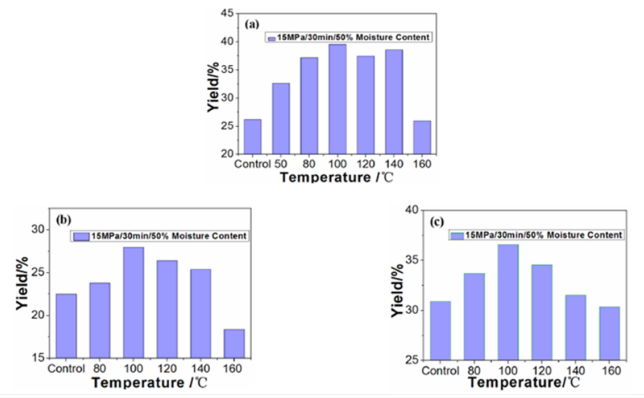

Fig. 21 Effect of pretreatment temperature on the hydrolysis of lignocellulosic biomass pretreated with supercritical $\mathrm{CO}_{2}$ at $15 \mathrm{MPa}$ and moisture content of $50 \%$ for $30 \mathrm{mins}$; (a) corn cob; (b) corn stalk; (c) rice straw [158]

\subsection{Biological pretreatment}

Delignification and reduction in degree of polymerization of cellulose and partial hydrolysis of hemicelluloses.Most of the pretreatment techniques are very expensive and increases the cost of the entire bio-fuel recovery process [41]. Physical and thermochemical pretreatment techniques involve use of expensive instruments \& equipments that require huge energy input [181]. Peroxidase and laccase are the enzymes responsible for lignin degradation and they occur in specific fungi [182]. Biological pretreatment involves both anaerobic and aerobic methods[57]. Certain enzymes like peptidase, carbohydrolase and lipase are added to AD systems widely utilizing OFMSW like paper pulp and WWTP sludge [57]. Some researchers consider the hydrolytic acidogenic step (first step) of two phase $\mathrm{AD}$ process as a biological pretreatment method [5],[183],[184],[185]. Two-stage AD processes are much more benefitial in terms of higher methane production and COD removal rate as compared to that of conventional one-stage digesters. In two-stage reactors, the sequential reactions occur in separate phases namely acid phase in the first stage and methane phase in the second stage. Necessary pretreatment applications have been applied to the first phase where acidogenesis and acetogenesis take place [57]. A double-stage $\mathrm{AD}$ process consists of hydrolysis stage and methanogenic stage. Certain advantages associated with the double stage process are: (i) better $\mathrm{pH}$ control; (ii) better stability of the process; (iii) better VS reduction i.e improved VS removal rate; (iv) enhanced specific activity of the methanogens and higher biogas yield; (v) easy removal of pathogens [8],[186],[187],[188],[189],[190]. A study by Verrier et al. reported $90 \%$ conversion of vegetable wastes to biogas utilizing a two stage reaction system that was capable of withstanding higher organic loads; the double stage system totally out-performed the performance of same vegetable wastes fed into conventional mesophilic and thermophilic single stage continuous stirred tank reactors (CSTRs) [191]. Adjustment of $\mathrm{pH}$ to 7 in first stage i.e neutral is easy for two stage system and improves both the total solids (TS) loading rate and biogas yield [192]. Nevertheless, despite the advantages of double stage $\mathrm{AD}$ process certain disadvantages do prevail which leads to controversial decision of using the conventional single stage reactors. The disadvantages associated are: (i) higher cost; (ii) technical complexity; (iii) choking of pumps; (iv) possible elimination of interdependent nutrients essential for methane producing bacteria [193],[194].

Biological pretreatment of lignocellulosic biomass using rot-fungi or rots is an eco-friendly and economic method that doesnot require any energy input for lignin degradation [27]. Fungi like brown, white and soft-rots are capable of degrading lignin and hemicellulose in lignocellulosic biomass, thereby making the cellulose available in the microfibrils for further enzymatic or acid hydrolysis [181]. Pretreatment of wheat straw was studied by using 19 rotfungi and resulted in 35\% conversion of straw to reducing sugars by Pleurotus ostreatus in 5 weeks [195]. Similar conversion was obtained in the pretreatment by Phanerochaete sordid [196] and Pycnoporus cinnabarinus[181] in 4 weeks. Miah et al. investigated AD process for biogas production from sewage sludge pretreated with aerobic thermophilic bacteria closely related to Geobacillus thermodentrificans [197]. Highest amount of biogas $(70 \mathrm{~mL} / \mathrm{gVS})$ with $80-90 \%$ methane content was achieved at $65{ }^{\circ} \mathrm{C}$. Certain fungi are also effective in treating the biomass to remove their recalcitrance. One such fungal species is Trametes pubescens; that have been subjected for pretreatment of wine distillery water waste [198]. This fungal pretreatment obtained a 53.3\% COD removal efficiency which increased the total COD removal efficiency of the AD system upto 99.5\% [198]. Biodegradation of bermuda-grass stems have been improved by $29-32 \%$ after 6 weeks, using Ceriporiopsis subvermispora and by 63-77\% using Cyathus stercoreus [199]. Japanese red pine Pinus densiflora have been pretreated by three kinds of white-rot fungi: Ceriporia lacerata, Stereum hirsutum and Polyporus brumalis [182]. After 8 weeks of pretreatment, S. hirsutum selectively degraded the lignin present in wood sample rather than holocellulose component. Wood-rot fungi have also been tested for bio-pretreatment of wood to obtain ease in separation of wood components further by ethanolysis [200]. Beech wood chips have been pretreated with whiterot fungi for 2-8 weeks and further applied for ethanolysis to separate into pulp and soluble fractions.

Elemental analysis of biomass/waste is essential [41]. The $\mathrm{C} / \mathrm{N}$ ratio is important for biomass pretreatment as certain amount of nitrogen is required by the microbes to degrade each molecule of carbon present in the biomass [41]. The requirement of nitrogen for carbon molecule degradation depends upon the microflora [41]. In general agreement with literature, it have been observed that fungi are more capable of degrading lignocellulosic biomass than 
Aritra Das, Chanchal Mondal and Shyamal Roy/

Journal of Engineering Science and Technology Review 8 (5) (2015) 141-165

bacteria as their dependency on nitrogen is comparatively lower (C/N ratio for fungi \& bacteria are 30:1 \& 10:1 respectively) [201]. Microbial pretreatment of biomass trash (sugarcane) renders sugar more accessible for enzymatic hydrolysis. Microbes are great bioagents that synthesizes cellulases which in turn enzymatically hydrolyzes the sugarcane trash [41].

Temperature phased anaerobic digestion (TPAD) have been studied by researchers and reported that TPAD outperformed the conventional AD processes involved with dry digestion of source separated OFMSW [202]. This method usually consists of a primary digester operated at thermophilic or hyper-thermophilic conditions followed by a secondary digester operated at mesophilic conditions [57]. The advantages of TPAD process is not only higher methane yield but also pathogen free digestate that can be directly utilized for soil conditioning [203]. A study by Lee et al., reported TPAD achievements utilizing $\mathrm{FW}$ and excess sludge at $70{ }^{\circ} \mathrm{C}$ temperature of the first reactor and $35{ }^{\circ} \mathrm{C}, 55$ ${ }^{0} \mathrm{C}$ and $65{ }^{0} \mathrm{C}$ respectively for the secondary reactor [204]. Best result was achieved with $70{ }^{\circ} \mathrm{C}$ in the primary reactor and followed by $55{ }^{\circ} \mathrm{C}$ in the second reactor and a solid retention time of 4 days. Song et al., compared the biogas production and pathogen removal of waste with TPAD and conventional single-stage mesophilic and thermophilic digester [205]. TPAD resulted in higher (12-15\%) VS reduction and was observed to be as stable as single-stage mesophilic system and at the same time, pathogen removal was as high as single stage thermophilic reactor.

\subsection{Ammonia pretreatment}

Removal of hemicellulose and cellulose crystallinity is possible by pretreatment of lignocellulosic biomass using aqueous ammonia at elevated temperatures. Three types of pretreatment techniques have been studied namely AFEX (ammonia fiber explosion), ARP (ammonia recycle percolation) [27],[42] and SAA (soaking in aqueous ammonia). In ARP method, aqueous ammonia (10-15\%) passes through the biomass at elevated temperatures (150$170{ }^{\circ} \mathrm{C}$ ) [41]. The residence time is maintained as $14 \mathrm{mins}$ and a fluid velocity of $1 \mathrm{~cm} / \mathrm{min}$ is followed [41]. Soaking in ammonia resulted in loosening of the interactions of lignin and hemicelluloses as reported in a study by Kim et al [206], [207]. Upon lignin solubilization, the surface area and porosity of the biomass increased that rendered easy hydrolysis of the hemicellulose and cellulose to fermentable sugars by combined action of xylanase and cellulase. The study by $\mathrm{Kim}$ et al. involved pretreatment of de-starched barley hull with $15-30 \%$ aqueous ammonia at $30-75{ }^{0} \mathrm{C}$ for $12 \mathrm{~h}$ to 77 days with no agitation and solid to liquid ratio of $1: 12$ [208]. After relevant exposure to soaking in aqueous ammonia, the solids were recovered by filtration, washed and analyzed. As a result they obtained $66 \%$ lignin solubilization, yields of $83 \%$ glucan and $63 \%$ xylan when treating biomass with $15 \%$ aqueous ammonia at $75{ }^{\circ} \mathrm{C}$ during 48h. Cost of ammonia and ammonia recovery drives out the pretreatment technique [178],[209]. The ammonia pretreatment causes depolymerization of lignin and also cleavage of lignin-carbohydrate linkages. No inhibitory products are produced in the process of ammonia pretreatment and hence water wash of the pretreated biomass is not necessary.
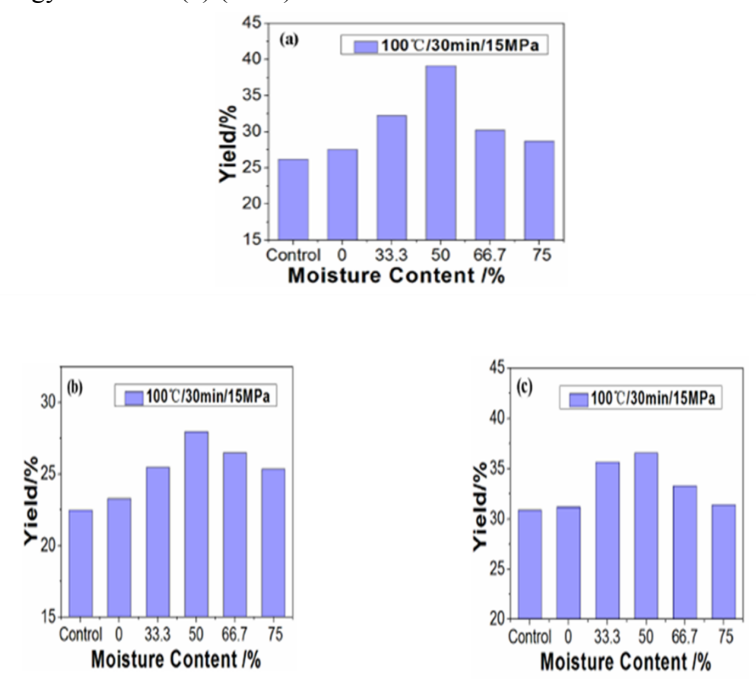

Fig. 22 Effect of moisture content of lignocellulose on the hydrolysis of lignocellulose pretreated with supercritical $\mathrm{CO}_{2}$ at $15 \mathrm{MPa}$ and $100{ }^{\circ} \mathrm{C}$ for 30mins; (a) corn cob; (b) corn stalk; (c) rice straw [158]

\subsection{Ionic Liquids}

Salts in liquid phase at low temperature (as low as room temperature) are known as RTIL (Room Temperature Ionic Liquids). Different kinds of RTIL are there and they share a common feature; consist of an inorganic anion and organic cation. Due to the heterogeneous molecular structure and weak bonding they exist in liquid state at room temperature [210]. Very few literatures have been found reporting about RTILs and yet there is no industrial application of RTIL for removal of lignin [211]. Though researchers considered the potential of RTIL for removal of lignin and cellulose accessibility for hydrolysis [29]. Due to the polarity and in general their unique properties, RTIL have been expected to behave as selective solvents for lignin removal, without use of acid or alkali and thereby formation of inhibitory compounds can also be avoided [79]. Due to lack of experience of implementing RTIL for lignin removal from lignocellulosic wastes disadvantages associated with RTIL are certain uncertainities regarding recovery process of RTILs, toxicity of the compounds and combination of water with RTIL [79].

\subsection{Delignification}

Lignin removal or delignification have been achieved in presence of peroxidase enzyme assisted by a strong oxidizing agent like hydrogen peroxide, ozone, oxygen or air [79],[212]. Delignification process have been successful due to high reactivity of the strong oxidizing chemicals with the aromatic rings of the polymer lignin [79]. These strong oxidizing agents also affect the hemicelluloses fraction on biomass and a substantial portion of hemicelluloses may be degraded and no longer be available for sugar production upon hydrolysis [79]. The most common oxidizing agent that have been used is $\mathrm{H}_{2} \mathrm{O}_{2}$ [41]. A study reported dissolution of about $50 \%$ lignin and almost all hemicelluloses using $2 \% \mathrm{H}_{2} \mathrm{O}_{2}$ at $30{ }^{\circ} \mathrm{C}$ within $8 \mathrm{~h}$ and $95 \%$ glucose recovered from cellulose by use of cellulase enzyme (saccharification) at $45{ }^{0} \mathrm{C}$ [212]. Wet air oxidation (WAO) have also been studied and regarded as an alternative process to steam explosion [213]. Wet oxidation method makes use of oxygen or air in combination with water at elevated temperature and pressure. Nevertheless, WAO have been implemented at industrial scale to treat wastes comprising of higher organic matter by oxidation of soluble or suspended 
Aritra Das, Chanchal Mondal and Shyamal Roy/

Journal of Engineering Science and Technology Review 8 (5) (2015) 141-165

matter with oxygen in aqueous phase at high temperatures $\left(150-350{ }^{\circ} \mathrm{C}\right)$ and pressure $(5-20 \mathrm{MPa})[214]$. Wet air oxidation have been successfully implemented for pretreatment of wheat straw and hardwood [215],[216]. Carboxylic acids, carbon dioxide and water are the main producers formed due to degradation of lignin and hemicellulose upon alkaline wet air oxidation. The crystalline structure of cellulose have been observed to open up during wet air oxidation and hence this method of pretreatment have been considered most effective in treating lignocellulosic biomass [217]. Likewise, the hemicelluloses of wood or saw dust have been observed to solubilize completely with wet air oxidation pretreatment method. A study reported $65 \%$ degree delignification using wheat straw as biomass [218]. A reported advantage of wet air oxidation method is very feeble production of furfural and 5hydroxymethylfurfural, which are potential inhibitors of fermentation step.

\section{Summary}

A wide array of lignocellulosic wastes are available for very low or negative cost that are suitable for biofuel production. Similarly, different pretreatment techniques are applicable for specific wastes and it is always not possible to compare the results of pretreatment from one type of material to another. Any single pretreatment method may not be sufficient for a specific biomass, instead a combination i.e sequential pretreatment methods have been more effective . Moreover, any particular pretreatment technique may not work for all kinds of waste. This justifies that the choice of pretreatment method depend on the composition of biomass taken for experiment. Pretreatment is the most cost effective step prior to anaerobic digestion process. Hence, entire process feasibility is dependant on this very crucial step of pretreatment. It is always expected to recover the invested cost of experiment to overcome at a later stage in terms of energy recovery. Maceration / grinding is the most simple pretreatment technique that helps in reducing cellulose crystallinity, though over particle size reduction have been observed to inhibit anaerobic digestion processes due to accumulation of organic acids, power consumption is usually higher than the inherent biomass energy. Steam explosion pretreatment method is easily achievable and causes hemicellulose degradation and lignin transformation (cost-effective); but this process is not suitable for biomass with high lignin content, generates inhibitory compounds for microorganisms. Another process namely AFEX (ammonia fiber explosion) \& carbon dioxide explosion increases accessible surface area of biomass, removes lignin and hemicellulose to certain extent and doesnot produce inhibitory compounds for microorganisms, but like steam explosion this process is not suitable for biomass with high lignin content. Pretreatment with inert gas like ozone, $\mathrm{O}_{3}$ i.e ozonolysis reduces lignin content and doesnot cause formation of inhibitory compounds, but this process is expensive as large amount of ozone is required. Acidic and alkaline pretreatment is effective for biomass with high lignin content. Acidic pretreatment hydrolyzes hemicelluloses to xylose and other sugars, alters the lignin structure; but high cost, equipment corrosion and formation of toxic substances are the disadvantages associated with the process. Alkaline hydrolysis is cheaper than the acidic process, but longer residence time, incorporation of irrecoverable salts into the biomass are the limitations. Pyrolysis also aid in effective hydrolysis of cellulose to glucose and xylose and produces gas and liquid products; high temperature requirement and ash production is the major hindrance of the process efficiency. Amongst all the processes, most economical and eco-friendly method is the biological pretreatment method that degrades lignin and hemicellulose with very low energy requirements; the only disadvantage of the process is that the rate of hydrolysis is very low. Other methods like oxidative delignification (wet oxidation using $\mathrm{H}_{2} \mathrm{O}_{2}$ followed by base addition), hydrothermal process, thermo-chemical process, thermomechanical process etc are more effective in cases of all the limitations mentioned above for all individual processes. Any effective preatreatment method or combined methods, should result in $10 \%$ lignin content in biomass. The amount of xylose and glucose obtained after hydrolysis is considered as the extent of effectiveness of any method or combined methods. Hence, the choice of pretreatment method always needs to be altered according to the biomass taken into consideration.

\section{Acknowledgements}

This research work has been financially supported by DST INSPIRE Fellowship for Doctoral studies (DST/INSPIRE Fellowship/2014 GOVT OF INDIA, MINISTRY OF SCIENCE and TECHNOLOGY) and research grant of the Department of Chemical Engineering, Jadavpur University. The same work has been efficiently assisted by Mr. Ashok Seal whose out reaching contribution to laboratory equipment handling made the work a success. Nevertheless, the work has been sequentially assisted time to time by Dr. Saswata Bose (Faculty, Department of Chemical Engineering, Jadavpur University). Henceforth deep sense of gratitude is expressed for everybody who contributed to the research work for making it a grand success.

\section{References}

1. Roubaud, A., Favrat, D. Improving performances of a lean burn cogeneration biogas engine equipped with combustion prechambers. Fuel 2005;84(16):2001-7.

2. Ghosh, S., Henry, MP., Sajjad, A., Mensinger, MC., Arora, JL. Pilot-scale gasification of municipal solid wastes by high-rate and two-phase anaerobic digestion (TPAD). Water Sci Technol 2000;41(3):101-10.

3. Lier, JB., Tilche, A., Ahring, BH., Macarie, H., Moletta, R., Dohanyos, $\mathrm{M}$ et al. New perspectives in anaerobic digestion. Water Sci Technol 2001;43:1-18.

4. Edelmann, W., Baier, U., Engeli, H. Environmental aspects of the anaerobic digestion of the OFMSW and agricultural wastes. Water Sci Technol 2005;52:553-9.
5. Carrere, H., Dumas, C., Battimelli, A., Batstone, DJ., Delgenes, JP., Steyer, JP et al.,Pretreatment methods to improve sludge anaerobic degradability: a review. J Hazard Mater 2010;183:1-15.

6. Sonesson, U., Bjorklund, A., Carlsson, M., Dalemo, M. Environmental and economic analysis of management systems for biodegradable waste. Resour Conserv Recycl 2000;28:29-53.

7. Esposito, G., Frunzo, L., Giardano, A., Liotta, F., Panico, A., Pirozzi, F. Anaerobic co-digestion of organic wastes, Review paper. Rev Environ Sci Biotechnol 2012;11:235-341.

8. Hartmann, H., Moller, HB., Ahring, BK. Efficiency of the anaerobic treatment of the organic fraction of municipal solid waste: collection and pretreatment. Waste Manage Res 2004;22:3541. 
Aritra Das, Chanchal Mondal and Shyamal Roy/

Journal of Engineering Science and Technology Review 8 (5) (2015) 141-165

9. Adney, WS., Rivard, CJ., Ming, SA., Himmel, ME. Anaerobic digestion of lignocellulosic biomass and wastes. Cellulases and related enzymes. Appl Biochem Biotechnol 1991;30(2):165-83.

10. Skiadas, IV., Gavala, HN., Lu, J., Ahring, BK. Thermal pretreatment of primary and secondary sludge at $70^{\circ} \mathrm{C}$ prior to anaerobic digestion. Water Sci Technol 2005;52:161-6.

11. Lu, J., Gavala, HN., Skiadas, IV., Mladenovska, Z., Ahring, BK. Improving anaerobic sewage sludge digestion by implementation of a hyper thermophilic pre-hydrolysis step. J Environ Manage 2008;88:881-9.

12. Carlsson, M., Lagerkvist, A., Morgan-Sagastume, F.,2012. The effects of substrate pretreatment on anaerobic digestion: a review. Waste Manage. 32,1634-1650.

13. Zaman, AU., 2013. Identification of waste management development drivers and potential emerging waste treatment technologies. Int. J. Environ. Sci. Technol. 10(3), 455-464.

14. Kirchmayr,R., Scherzer, R., Baggesen, D.1., Braun, R., Wellinger, A.,2003. Animal By-products and Anaerobic Digestion, Requirements of the European Regulation (EC) No. 1774/2002.,IEA Bioenergy Task 37, Energy from Biomethane and Landfill Gas in Cooperation with Bioexell - Biomethane Center of Excellence.

15. Zhang, R., El-Mashad, H.M., Hartman, K., Liu, G., Choate, C., Gamble, P., 2007. Characterization of food waste as feedstock for anaerobic digestion. Bioresour. Technol. 98, 929-935.

16. Montoneri, E., Savarino, P., Bottigliengo, S., Boffa, V., Prevot, AB., Fabbri, D., et al. Biomass wastes as renewable source of energy and chemicals for the industry with friendly environmental impact. Fresenius Environ Bull 2009;18(2):219-23.

17. Niee Liew, L., Shi, J., Li, Y., et al. Methane production from solidstate anaerobic digestion of lignocellulosic biomass. Biomass and Bioenergy 46(2012) 125-132.

18. Chandler, JA., Jewell, WJ., Gossett, JM., Vansoest, PJ., Robertson, JB. Predicting methane fermentation biodegradability. Biotechnol Bioeng 1980;22:93-107.

19. Bjorndal, KA., Moore, JE. Prediction of fermentability of biomass feedstocks from chemical characteristics. In: Smith WH, editor. Biomass energy development. New York: Plenum Press; 1985. p. 447-54.

20. Shi, J., Ebrik, M., Yang, B., Wyman, CE. The potential of cellulosic ethanol production from municipal solid waste: a technical and economical evaluation. Berkeley, CA: Development of Technology, University of California Energy Institute; 2009.

21. Iranmahboob, J., Nadim, F., Monemi, S. Optimizing acid hydrolysis: A critical step for production of ethanol from mixed wood chips. Biomass Bioenergy2002, 22, 401-404.

22. Broder, J.D., Barrier, J.W., Lee, K.P., Bulls, M.M. Biofuels system economics. World Resour. Rev. 1995, 7(4), 560-569.

23. Mosier, N.S., Wyman, C., Dale, B., Elander, R., Lee, Y.Y., Holtzapple, M., Ladisch, M.R. Features of promising technologies for pretreatment of lignocellulosic biomass. Bioresour Technol. 2005, 96, 673-686.

24. Lynd, L.R., Elander, R.T., Wyman, C.E. Likely features and cost of mature biomass ethanol technology, Appl, Biochem. Biotechnol. 1996, 57(58), 741-761.

25. Lee, J. Biological conversion of lignocellulosic biomass to ethanol. J. Biotechnol. 1997, 56, 1-24.

26. Lee, D., Yu, A.H.C., Wong, K.K.Y., Saddler, J.R. Evaluation of the enzymatic susceptibility of cellulosic substrates using specific hydrolysis rates and enzyme adsorption. Appl . Biochem. Biotechnol. 1994, 45(45), 407-415.

27. Galbe, M., Zacchi, G. Pretreatment of lignocellulosic materials for efficient bioethanol production. Adv. Biochem. Eng./Biotechnol. 2007, 108, 41-65.

28. Perez, J., Dorado, J.M., Rubia, T.D., Martinez, J. Biodegradation and biological treatment of cellulose, hemicellulose and lignin: an overview. Journal of International Microbiology 2002;5:53-63.

29. Chandra, R., Takeuchi, H., Hasegawa, T. Methane production from lignocellulosic agricultural crop wastes: A review in context to secong generation of biofuel production. Renewable and Sustainable Energy Reviews 16 (2012) 1462-1476.

30. Jorgensen, H., Kristensen, J.B., Felby, C. Enzymatic conversion of lignocellulose into fermentable sugars: Challenges and opportunities. Biofuels, Bioprod, Bioref. 2007, 1, 119-134.

31. Jorgrnsen H, Kristensen JB, Felby C. Enzymatic conversion of lignocellulose into fermentable sugars: challenges and opportunities. Journal of Biofuels, Bioproducts \& Biorefining 2007; $1(2): 119-34$.
32. Sjostrom E. Wood chemistry: fundamentals and applications. San Diego, USA: Academic Press; 1993.

33. Sims R. Biomass and resources bioenergy options for a cleaner environment in developed and developing countries. London: Elsevier Science; 2003.

34. Delmer DP., Amor Y.Cellulose biosynthesis. Journal of plant cell 1995; 7:987-1000.

35. Morohoshi N. Chemical characterization of wood and its components. In: Hon DNS, Eds NS, Dekker M editors. Wood and cellulosic chemistry. New York, USA: Academic Press; 1991.p. 331-92.

36. Ha MA., Apperley DC., Evans BW., Huxham IM., Jardine WG., Vietor RJ, et al. Fine structure in cellulose microfibrils: NMR evidence from onion and quince. Journal of plant 1998;16:183-90.

37. Beguin P., Aubert JP. The biological degradation of cellulose. Journal of FEMS Microbiology Review 1994;13:25-58.

38. Perez J., Dorado JM., Rubia TD., Martinez J. Biodegradation and biological treatment of cellulose, hemicellulose and lignin: an overview. Journal of International Microbiology 2002;5:53-63.

39. Taherzadeh MJ. Ethanol from lignocellulose: Physiological effects of inhibitors and fermentation strategies. Ph.D thesis. Biotechnology, Chemical Reaction Engineering, Chalmers University of Technology; 1999.

40. Palmqvist E., Hahn-Hagerdal B. Fermentation of lignocellulosic hydrolysates II: inhibitors and mechanisms of inhibition. Journal of Bioresource Technology 2000;74:25-33.

41. Kumar P., Barrett D.M., Delwiche M.J., Stroeve P. Methods for pretreatment of lignocellulosic biomass for efficient hydrolysis and biofuel production. Ind Eng Chem Res. 20 March 2009.

42. Sun Y., Cheng J. Hydrolysis of lignocellulosic materials for ethanol production: A review. Bioresour Technol. 2002,83,1-11.

43. Millet, M. A.; Baker, A. J.; Scatter, L. D. Physical and chemical pretreatment for enhancing cellulose saccharification.Biotech. Bioeng. Symp. 1976, 6, 125-153.

44. Zhu B., Gikas P., Zhang R., Lord J., Jenkins B., Li X. Characteristics and biogas production potential of municipal solid wastes pretreated with rotary drum reactor. Bioresour Technol 2009;100:1122-9.

45. Subramani T., Ponkumar S. Anaerobic digestion of aerobic pretreated organic waste. Int J Modern Eng Res 2012;2:607-11

46. Davidson A, Gruvberger C, Christensen TH, Hansen TL, Jansen JC. Methane yield in source-sorted organic fraction of municipal solid waste. Waste Manage 2007;27:406-14.

47. Zhang Y., Banks CJ. Impact of different particle size distributions on anaerobic digestion of the organic fraction of municipal solid waste. Waste Manage 2013;33:297-307.

48. Hansen TL., Jansen JC., Davidsson A., Christensen TH. Effects of pre-treatment technologies on quantity and quality of source-sorted municipal organic waste for biogas recovery. Waste Manage 2007;27:389-405.

49. Mata-Alvarez J., Mace S., Llabres P. Anaerobic digestion of organic solid wastes. An overview of research achievements and perspectives. Bioresour Technol 2000;74:3-16.

50. Barjenbruch M., Kopplow O. Enzymatic, mechanical and thermal pre-treatment of surplus sludge. Adv Environ Res 2003;7:715-20.

51. Izumi K., Okishio YK., Niwa C., Yamamoto S., Toda T. Effects of particle size on anaerobic digestion of food waste. Int Bio-deterior Biodegr 2010;64:601-8.

52. Li Y., Park SY., Zhu J. Solid-waste anaerobic digestion for methane production from organic waste. Renew Sustain Energy Rev2011;15:821-6.

53. Carrere H., Dumas C., Battimelli A., Batstone DJ., Delgenes JP, Steyer JP., et al. Pretreatment methods to improve sludge anaerobic degradability: a review. J Hazard Mater 2010;183:1-15.

54. Angelidaki I., Ahring BK. Methods for increasing the biogas potential from the recalcitrant organic matter contained in manure. Water Sci Technol 2000;41:189-94.

55. Toreci I., Kennedy KJ., Droste RL. Evaluation of continuous mesophilic anaerobic sludge digestion after high temperature microwave pre-treatment. Water Res 2009;43:1273-84.

56. Perez-Elvira S1., Nieto Diez P., Fdz-Polanco F. Sludge minimization technologies. Rev. Environ. Sci. Bio/Technol. 2006;5:375-98.

57. Ariunbaatar J., Panico A., Esposito G., Pirozzi F., Lens N.L P. Pretreatment methods to enhance anaerobic digestion of organic solid waste. Applied Energy 123(2014) 143-156. 
Aritra Das, Chanchal Mondal and Shyamal Roy/

Journal of Engineering Science and Technology Review 8 (5) (2015) 141-165

58. Cesaro A., Belgiorno V. Pretreatment methods to improve anaerobic biodegradability of organic municipal solid waste fractions. Chem Eng J 2014;240:24-37.

59. Edelmann W., Baier U., Engeli H. Environmental aspects of the anaerobic digestion of the OFMSW and agricultural wastes. Water Sci Technol 2005;52:553-9.

60. Val del Rio A., Morales N, Isanta E., Mosquera-Corral A., Campos JL., Steyer JP et al.Thermal pretreatment of aerobic granular sludge: impact on anaerobic biodegradability. Water Res 2011;45:6011-20.

61. Liu X., Wang W., Gao X., Zhou Y., Shen R. Effect of thermal pretreatment on the physical and chemical properties of municipal biomass waste. Waste Manage 2012;32:249-55.

62. Ferrer I., Ponsa S., Vasquez F., Font X. Increasing biogas production by thermal $\left(70{ }^{\circ} \mathrm{C}\right)$ sludge pre-treatment prior to thermophilic anaerobic digestion. Biochem Eng J 2008;42:186-92.

63. Marin J., Kennedy KJ., Eskicioglu C. Effect of microwave irradiation on anaerobic degradability of model kitchen waste. Waste Manage 2010;30:1772-9.

64. Protot A., Julien L., Christophe D., Patrick L. Sludge disintegration during heat treatment at low temperature: a better understanding of involved mechanisms with a multi-parametric approach. Biochem Eng J 2011;54:178-84.

65. Bien JB., Malina G., Bien JD., Wolny L. Enhancing anaerobic fermentation of sewage sludge for increasing biogas generation. $J$ Environ Sci Health 2004;39:939-49.

66. Mottet A., Steyera JP., Delerisb S., Vedrenneb F., Chauzyc J., Carrere H. Kinetics of thermophilic batch anaerobic digestion of thermal hydrolysed waste activated sludge. Biochem Eng $J$ 2009;46:169-75.

67. Hendriks ATWM., Zeeman G. Pretreatments to enhance the digestibility of lignocellulosic biomass: a review. Bioresour Technol 2009;100:10-8.

68. Bougrier C., Albasi C., Delgenes JP., Carrere H. Effect of ultrasonic, thermal and ozone pretreatments on waste activated sludge solubilization and anaerobic biodegradability. Chem Eng Process 2006;45:711-8.

69. Elliot A., Mahnood T. Comparison of mechanical pretreatment methods for the enhancement of anaerobic digestion of pulp and paper waste. Water Sci Technol 2012;84:497-505.

70. Penaud V., Delgenes JP., Moletta R. Thermo-chemical pretreatment of a microbial biomass: influence of sodium hydroxide addition on solubilization and anaerobic biodegradability. Enzyme Microbial Technol 1999;25:258-63.

71. Pinnekamp J. Effects of thermal pretreatment of sewage sludge on anaerobic digestion. Water Sci Technol 1989;21:97-108

72. Ma J., Duong TH., Smits M., Vestraete W., Carballa M. Enhanced biomethanation of kitchen waste by different pretreatments Bioresour Technol 2011;102:592-9.

73. Rafique R., Poulse TG., Nizami A-S., Asam ZZ., Murphy JD., Kiely G. Effect of thermal, chemical and thermo-chemical pretreatments to enhance methane production. Energy 2010;35:4556-61.

74. Ariunbaatar J., Panico A., Frunzo L., Esposito G., Lens N.L P., Pirozzi F. Enhanced anaerobic digestion of food waste by thermal and ozonation pretreatment methods. Journal of Environmental Management 146(2014) 142-149.

75. Appels L., Degreve J., Bruggen BV., Impe JV., Dewil R. Influence of low temperature thermal pre-treatment on sludge solubilization, heavy metal release and anaerobic digestion. Bioresour Technol 2010;101:5743-8.

76. Chamchoi N., Garcia H., Angelidaki I. Methane potential of household waste; batch assays determination. J Environ Resour 2011;33:13-26.

77. Climent M., Ferrer I., Baeza MM., Artola A., Vazquez F., Font X. Effect of thermal, mechanical pretreatments of secondary sludge on biogas production under thermophilic conditions. Chem Eng J2007 ;133:335-42.

78. Tchobanoglous G., Theisen H., Vigil S.A., 1993. Integrated solid waste Management. ISBN 0071128654, 9780071128650.

79. Harmsen P.F.H., Huijgen W.J.J., Lopez Bermudez L.M., Bakkar R.R.C. Literature review of physical and chemical pretreatment processes for Lignocellulosic Biomass. ECN BIOSYNERGY, Food and bio-based research Wageningien.

80. O'Connor,R.P., R Woodley., J.J Kolstad., R Kean., D.A Glassner., B. Mastel., J.M Ritzenthaler, H John., J Warwick., J.R Hettenhaus \& R.K Brooks (2007): Process for fractionating lignocellulosic biomass into liquid and solid products. Assignee USA Nature Works L.L.C, patent no WO 2007120210.

81. Fan, L.T., Gharpuray, M.M., Lee Y.H. Cellulose hydrolysis; Biotechnology Monographs; Springer: Berlin; Vol.3, p 57.

82. Li H., Chenchen Li., Liu W., Zou S. Optimized alkaline pretreatment of sludge before anaerobic digestion. Bioresource Technol 2012;123:189-94.

83. Wang L., Mattsson M., Rundstedt J., Karlsson N. Different pretreatments to enhance biogas production. Master of Science Thesis. Halmstad University; 2011.

84. Carballa M., Manterola G., Larrea L., Ternes T., Omil F., Lema J.M., 2007. Influence of ozone pretreatment on sludge anaerobic digestion: removal of pharmaceutical and personal care products. Chemosphere 67, 1444-1452.

85. Quesada, J., Rubio, M., Gomez, D. Ozonation of Lignin Rich Solid Fractions from Corn Stalks. J. Wood Chem Technol. 1999, 19, 115137.

86. Ben-Ghedalia, D., Miron J. The effect of combined chemical and enzyme treatment on the saccharification and in vitro digestion rate of wheat straw. Biotechnol. Bioeng. 1981,23,823-831.

87. Neely, W.C. Factors affecting the pretreatment of biomass with gaseous ozone. Biotechnol. Bioeng. 1984,26,59-65.

88. Ben-Ghedalia, D., Shefet, G. Chemical treatments for increasing the digestibility of cotton straw. J. Agric.Sci. 1983,100,393-400.

89. Vidal, P.F., Molinear, J. Ozonolysis of lignin - Improvement of in vitro digestibility of poplar saw dust. Biomass 1988,16,1-17.

90. Modenbach AA., Nokes SE. The use of high-solids loading in biomass pretreatment - a review. Biotechnol Bioeng 2012;109:1430-42.

91. Lopez Torres M, del Espinosa Llorens Ma. Effect of alkaline pretreatment on anaerobic digestion of solid wastes. Waste manage 2008;28:2229-34.

92. Kim J., Park C., Kim T., Lee M., Kim S et al. Effect of various pretreatment for enhanced anaerobic digestion with waste activated sludge. J Biosci Bioeng 2003;95:271-5.

93. Elshafei, A.M., Vega, J.L., Klasson, K.T., Clausen, E.C., Gaddy, J.L. The saccharification of corn stover by cellulase fromPenicillin funiculosum. Bioresour. Technol. 1991, 35,73-80.

94. Soto, M.L., Dominguez, H., Nunez, M.J., Lema, J.M. Enzymatic saccharification of alkali-treated sunflower hulls. Bioresour. Technol. 1994, 49, 53-59.

95. Fox, D.J., Gray, P.P., Dunn, N.W., Warwick, L.M. Comparison of alkali and steam (acid) pretreatments of lignocellulosic materials to increase enzymatic susceptibility: Evaluation under optimized pretreatment conditions. J.Chem. Tech. Biotech. 1989, 44,135-146.

96. MacDonald, D.G., Bakshi, N.N., Mathews, J.F., RoyChowdhury A., Bajpai, P., Moo Young, M. Alkali treatment of corn stover to improve sugar production by enzymatic hydrolysis. Biotechnol. Bioeng. 1983,25,2067-2076.

97. Kim IS., Kim DH., Hyun SH. Effect of particle size and sodium ion concentration on anaerobic thermophilic food waste digestion. Water Sci Technol 2000;41:67-73.

98. Soto, M., Mendez, R., Kema, JM. Sodium inhibition and sulphate reduction in the anaerobic treatment of mussel processing wastewaters. J Chem Technol Biotechnol 1993;58:1-7.

99. Bashir Basharat H., Matin Asif. Combined effect of calcium and sodium on potassium toxicity in anaerobic treatment processes, $<$ http://www.aseanenvironment.info/Abstract/41015401.pdf $>$

100. Kugelman IJ, McCarty P.L. Cation toxicity and stimulation in anaerobic waste treatment. J Water Pollut Control Fed 1965;37:97 $-116$.

101.Schmidt JE., Ahring BK. Effects of magnesium on thermophilic acetate degrading granules in upflow anaerobic sludge blanket (UASB) reactors. Enzyme Microb Technol 1993;15:304 - 10.

102. Zhang B., Zhang SC., Shi HZ., Cai WM. The influence of $p H$ on hydrolysis and acidogenesis of kitchen wastes in two-phase anaerobic digestion. Environ Technol 2005;26:329-39.

103.Zhang L., Jahng D. Long term anaerobic digestion of food waste stabilized by trace elements. Waste Manage 2012;32:1509-15.

104.Facchin V., Cavinato C., Fatone F., Pavan P., Cecchi F., Bolzonella D. Effect of trace element supplementation on the mesophilic anaerobic digestion of food waste in batch trials: the influence of inoculum origin. Biochem Eng J 2013;70:71 - 7.

105.Kim, S., Holtzapple, M.T. Effect of structural features on enzyme digestibility of corn stover. Bioresour. Technol. 2006, 97, 583-591.

106.Chang, V.S., Nagwani, M., Holtzapple, M.T. Lime pretreatment of crop residues bagasse and wheat straw. Appl. Biochem. Biotechnol. 1998, 74, 135-159. 
Aritra Das, Chanchal Mondal and Shyamal Roy/

Journal of Engineering Science and Technology Review 8 (5) (2015) 141-165

107. Chang, V.S., Nagwani, M., Kim, C.H., Holtzapple, M.T. Oxidative lime pretreatment of high-lignin biomass. Appl. Biomass. Biotechnol. 2001,94,1-28.

108.Chang, V.S., Burr, B., Holtzapple, M.T. Lime pretreatment of switchgrass. Appl.Biochem. Biotechnol. 1997, 63-65, 3-19.

109.Kong, F., Engler, C.R., Soltes, E.J. Effects of cell-wall acetate, xylan backbone, and lignin on enzymatic hydrolysis of aspen wood. Appl Biochem. Biotechnol. 1992 34/35, 23-35.

110.Bjerre, A.B., Olesen, A.B.,Fernqvist, T. Pretreatment of wheat straw using combined weight oxidation and alkaline hydrolysis resulting in convertible cellulose and hemicellulose. Biotechnol Bioeng. 1996, 49, $568-577$.

111. Chosdu, R., Hilmy, N.E., Erlinda, T.B., Abbas, B. Radiation and chemical pretreatment of cellulosic waste. Radiat. Phys. Chem. 1993,42, 695-698.

112. Neves, L., Ribeiro, R., Oliveira, R., Alves, M.M. Enhancement of methane production from barley waste. Biomass Bioenergy 2006;30:599-603.

113.Patil, JH., AntonyRaj, M., Gavimath, CC. Study on effect of pretreatment methods on biomethanation of water hyacinth. Int $J$ Adv Biotechnol Res 2011;2:143 - 7 .

114.Hu, Z., Wang, H., Wen, Z. Alkali (NaOH) Pretreatment of switchgrass by radio-frequency based dielectric heating. Appl. Biochem. Biotechnol. 2008, 148, 71-81.

115.Hu, Z., Wen, Z. Enhancing enzymatic digestibility of switchgrass by microwave assisted alkali pretreatment. Biochem. Eng. J. 2008, $38,369-378$.

116.Iyer, V., Wu, Z.W., Kim, S.B., Lee, Y.Y. Ammonia recycled percolation process for pretreatment of herbaceous biomass. Appl. Biochem. Biotechnol. 1996, 57/58, 121-132.

117.Sivers, M.V., Zacchi, G. A techno-economical comparison of three processes for the production of ethanol from pine. Bioresour. Technol. 1995, 51,43-52.

118.Root, D.F., Saeman, J.F., Harris, J.F. Kinetics of the acid catalyzed conversion of xylose to furfural. Forest Prod. J. 1959,158,165.

119.Zeitsch, K.J. The Chemistry and Technology of Furfural and Its Many By-products; Sugar Series; Elsevier: New York, 2000; Vol. 13.

120.Esteghlalian, A., Hashimoto, A.G., Fenske, J.J., Penner, M.H. Modelling and optimization of the dilute-sulfuric-acid pretreatment of corn stover, poplar and switch grass. Bioresour. Technol. 1997, $59,129-136$

121.Thompson, D.N., Chen, H.-C., Grethlein, H.E. Comparison of pretreatment methods on the basis of available surface area. Bioresour. Technol. 1991, 39, 155 - 163.

122.Lu, X.B., Zhang, Y.M., Yang, J., Liang, Y. Enzymatic hydrolysis of corn stover after pretreatment with dilute sulfuric acid. Chem. Eng. Technol. 2007, 30(7), $938-944$.

123.Ishizawa, C.I., Davis, M.F., Schell, D.F., Hohnson, D.K. Porosity and its effect on the digestibility of dilute sulfuric acid pretreated corn stover. J. Agric. Food Chem. 2007, 55, 2575 - 2581.

124.Wyman, C.E., Dale, B.E., Elander, R.T., Holtzapple, M., Ladisch, M.R., Lee, Y.Y. Coordinated development of leading biomass pretreatment technologies. Bioresour. Technol. 2005,96,1959 1966.

125.Selig, M.J., Viamajala, S., Decker, S.R., Tuker, M.P., Himmel, M.E. Deposition of lignin droplets produced during dilute acid pretreatment of maize stems retards enzymatic hydrolysis of cellulose. Biotechnol. Prog. 2007, 23, 1333 - 1339.

126.Valo, A., Carrere, H, Delgenes, JP. Thermal, chemical and thermochemical pretreatment of waste activated sludge for anaerobic digestion. J Chem Technol Biotechnol 2004;79:1197 - 203.

127.Shahriari, H., Warith, M., Hamoda, M., Kennedy, KJ. Anaerobic digestion of organic fraction of municipal solid waste combining two pretreatment modalities, high temperature microwave and hydrogen peroxide. Waste Manage 2012;32:41 - 52.

128.Carrere, H., Sialve, B., Bernet, N. Improving pig manure conversion into biogas by thermal and thermo-chemical pretreatments. Bioresour Technol 2009;100:3690 - 4 .

129. Wett. B., Phothilangka, P., Eladawy, A. Systematic comparison of mechanical and thermal sludge disintegration technologies. Waste Manage 2010;30:1057 - 62.

130.Schieder, D., Schneider, R., Bischof, F. Thermal hydrolysis (TDH) as a pretreatment method for the digestion of organic waste. Water Sci Technol 2000;41:181-7.

131.Qiao, W., Yan, X., Ye, J., Sun, Y., Wang, W., Zhang, Z. Evaluation of biogas production from different biomass wastes with/without hydrothermal pretreatment, Renewable Energy 36(2011) 3313 3318.

132. Xia, Z., Wang, W., Wang, ZJ. Study on pilot experiment of low pressure oxidation (LPO) of municipal sewage sludge. Journal of Harbin University of Commerce 2005;21(2):153 - 6.

133. Qiao, W., Wang, W., Wang, X. Improve sludge dewatering performance by hydrothermal treatment. Journal of Residuals Science\& Technology 2010;7(1):7 - 11.

134. Haug, RT., Stucky, DC., Gossett, JM. Effect of thermal pretreatment on digestibility and dewaterability of organic sludges. Journal of the Water Pollution Control Federation 1978;50(1):73 8.

135. Li, YY., Noikeal, T., Upgradation of anaerobic digestion of waste activated sludge by thermal pretreatment. Water Science and Technology 1992;26(3-4): $857-66$.

136. Glasser, WG., Wright, RS., (1998). Steam assisted biomass fractionation. II. Fractionation behavior of various biomass resources. Biomass and Bioenergy. 14:219-235.

137. Boussaid, A., Estrghlalian, R., Gregg, J., Lee, KE., Saddler, JN (2000). Steam pre-treatment of Douglas Fir Wood Chips. Applied biochemistry and biotechnology. $84-86: 693-705$.

138. Shevchenko, SM., Chang, K., Dick, DG., Gregg, DJ., Saddler, JN (2001). Structure and properties of lignin in softwoods after $\mathrm{SO}_{2}$ catalyzed steam explosion and enzymatic hydrolysis. Cellulose Chemistry and Technology 35 (5-6):487 - 502.

139. Bura, R., Mansfield SD., Saddler, JN., Bothast, JR (2002). $\mathrm{SO}_{2}$ catalyzed steam explosion of corn fiber for ethanol production. Applied biochemistry and biotechnology $98-100: 59-72$.

140. Garrote, G., Dominguez, H., Parajo, JC (1999). Hydrothermal processing of lignocellulosic materials. Holzforschung. 57:191 202.

141. Kokta, BV., Ahmed, A (1998). Chapter 6, Steam Explosion Pulping, Environmentally friendly technologies for the Pulp and Paper Industry. John Wiley \& Sons, Inc.

142. Cara, C., Ruiz, E., Ballesteros, I., Negro, MJ., Castro, E (2006). Enhanced enzymatic hydrolysis of olive tree wood by steam explosion and alkaline peroxide delignification. Process biochemistry $41(2): 423-429$.

143. Dererie, DY., Trobro, S., Momeni, MH., Hansson, H., Blomqvist, J., Passoth, V., Schnurer, A., Sandgren, M., Stahlberg, J (2011). Improved bioenergy yields via sequential ethanol fermentation and biogas digestion of steam exploded oat straw. Bioresource Technology 102(6):4449 - 4454.

144. Adapa, P., Tabil, L, Schoenau, G, Opoku, A (2010). Pelleting characteristics of selected biomass with and without steam explosion pretreatment. International Journal of Agriculture and Biological Engineering. 3(3): $62-79$.

145. Adapa, P., Tabil, L., Schoenau, G (2010a). Compression characteristics of non-treated and steam exploded Barley, Canola, Oat and wheat straw grinds. Applied Engineering in Agriculture. 26(4) :617-632.

146. Grous, W.R., Converse, A.O., Grethlein, H.E. Effect of steam explosion pretreatment on pore size and enzymatic hydrolysis of poplar. Enzyme Microb. Technol. 1986,8,274-280.

147. Li, J., Henriksson, G., Gellerstedt, G. Lignin depolymerization/repolymerization and its critical role for delignification of aspen wood by steam explosion. Bioresour. Technol.

148. Duff, S., J.B, Murray., W.D. Bioconversion of forest products industry waste cellulosics to fuel ethanol: A review. Bioresour. Technol. 1996,55, 1 -33.

149. Wright, J.D. Ethanol from biomass by enzymatic hydrolysis. Chem. Eng. Prog. 1998, 84, $62-74$.

150. Weil, J.R., Sarikaya, A., Rau, S.-L., Goetz, J., Ladisch, C.M., Brewer, M., Hendrickson, R., Ladisch, M.R. Pretreatment of yellow poplar sawdust by pressure cooking in water. Appl. Biochem. Biotechnol. 1997, 68 ( 1 -2,21-40)

151.Baugh, K.D., Levy, J.A., McCarty, P.L. Thermochemical pretreatment of lignocellulose to enhance methane fermentation: I. Monosaccharide and furfurals hydrothermal decomposition and product formation Rates. Biotechnol. Bioeng. 1988, 31,50-61.

152. Morjanoff, P.J., Gray, P.P. Optimization of steam explosion as method for increasing susceptibility of sugarcane bagasse to enzymatic saccharification. Biotechnol. Bioeng. 1987, 29, $733-$ 741 .

153. Ballesteros, I., Negro, M.J., Oliva, J.M., Cabanas, A., Manzanares, P., Ballesteros, M. Ethanol production from steam explosion 
Aritra Das, Chanchal Mondal and Shyamal Roy/

Journal of Engineering Science and Technology Review 8 (5) (2015) 141-165

pretreated wheat straw. Appl. Biochem. Biotechnol. 2006, 70 - 72, $3-15$.

154. Stenberg, K., Tengborg, C., Galbe, M., Zacchi, G. Optimization of steam pretreatment of $\mathrm{SO}_{2}$ impregnated mixed softwoods for ethanol production. J. Chem. Technol. Biotechnol. 1998, 71, $299-308$.

155. Kobayashi, F., Take, H., Asada, C., Nakamura, Y. Methane production from Steam-Exploded Bamboo. J.Biosci.Bioeng. 2004,97(6), 426-428.

156. Mackie, K.L., Brownell, H.H., West, K.L., Saddler,J.N. Effect of sulphur dioxide and sulphuric acid on steam explosion of aspenwood. J. Wood Chem. Technol. 1985,5,405 - 425.

157. McMillan, J.D. Pretreatment of lignocellulosic biomass. In Enzymatic Conversion of Biomass for Fuels Production; Himmel, M.E., Baker, J.O., Overend, R.P., Eds.; American Chemical Society: Washington, DC, 1994; pp $292-324$.

158. Liu, Y.F., Luo, P., Xu, Q.Q., Wang, E.J., Yin, J.Z. Investigation of the effect of supercritical carbon dioxide pretreatment on reducing sugar yield of lignocellulose hydrolysis. Cellulose Chemistry and Technology.

159. Gao, M., Xu, F., and Li, S et al. Pretreatment of Lignocellulosic Biomass Using Supercritical Carbon Dioxide as a Green Solvent, Biosyst. Eng., 106, 470 (2010).

160. Kim, K.H and Hong, J. Supercritical $\mathrm{CO}_{2}$ pretreatment of lignocelluloses enhances enzymatic cellulose hydrolysis. Bioresource Technol., 77, 139 (2001).

161. Narayanaswamy, N., Faik, A., Goetz, D.J et al. Supercritical carbon dioxide pretreatment of corn stover and switch grass for lignocellulosic ethanol production. Bioresource. Technol., 102, 6995 (2011).

162. Luterbacher, J.S., Tester, J.W and Walker, L.P. Two temperature stage biphasic $\mathrm{CO}_{2}-\mathrm{H}_{2} \mathrm{O}$ pretreatment of lignocellulosic biomass at high solid loadings. Biotechnol. Bioeng., 109, 6 (2012).

163. Moharreri, E., Ph.D Thesis, The University of Akron, Akron, OH, 2011.

164. Luterbacher, J.S., Tester, J.W and Walker, L.P,High-solids biphasic $\mathrm{CO}_{2}-\mathrm{H}_{2} \mathrm{O}$ pretreatment of lignocellulosic biomass. Biotechnol. Bioeng., 107, 451 (2010).

165. Alinia, R., Zabihi, S., Esmaeilzadeh et al. Pretreatment of wheat straw by supercritical $\mathrm{CO}_{2}$ and its enzymatic hydrolysis for sugar production. Biosyst. Eng., 107, 61 (2010).

166.Srinivasan, N., Ju, L.K. Pretreatment of guayule biomass using supercritical carbon dioxide-based method. Bioresource Technol., 101, 9785 (2010).

167. Srinivasan, Ph.D Thesis. The University of Akron, Akron, OH, 2010.

168. Zheng, Y., Tsao, G.T. Avicel hydrolysis by cellulase enzyme in supercritical $\mathrm{CO}_{2}$ Biotechnol. Lett., 18, 451 (1996).

169. Zheng, Y., Lin, H.M., Wen, J et al. Supercritical carbon dioxide explosion as a pretreatment for cellulose hydrolysis. Biotechnol. Lett ., 17, 845 (1995).

170. Turn, SQ., Kinoshita, CM., Kaar, WE., Ishiimura, D.M (1998) Measurements of gas phase carbon in steam explosion biomass. Bioresource Technology 64(1): 71- 75.

171. Laser, M., Schulman, D., Allen, S.G etal.A comparison of liquid hot water and steam pretreatments of sugarcane bagasse for bioconversion to ethanol. Bioresource Technol., 81, 33 (2002).

172. Converse, A.O., Kwarteng, I.K., Grethlein, H.E etal. Kinetics of thermochemical pretreatment of lignocellulosic materials. Appl. Biochem. Biotechnol., 20(1), 63(1989).

173. Kubo, S., Uraki, Y., Sano, Y. Thermomechanical analysis of isolated lignins. Holzforschung, 50, 144 (1996).

174. Dale, B.E., Moreira, M.J. A freeze explosion technique for increasing cellulose hydrolysis. Biotechnol. Bioeng. Symp. 1982, $12,31-43$.

175. Zheng, Y.Z., Lin, H.M., Tsao, G.T. Pretreatment for cellulose hydrolysis by carbon dioxide explosion. Biotechnol. Prog. 1998, 14, $890-896$.

176. Teymouri, F., Laureano - Perez, L., Alizadeh, H., Dale, B.E. Optimization of the Ammonia Fiber Explosion (AFEX) Treatment Parameters for Enzymatic Hydrolysisof Corn Stover. Department of Chemical Engineering and Material Science, 2527 Engineering Building, Michigan State University, East Lansing, MI48824.

177.Teymouri, F., Perez, L.L., Alizadeh, H., Dale, B.E. Ammonia fiber explosion treatment of corn stover. Appl. Biochem. Biotechnol. 2004, $113-116,951-963$.

178. Holtzapple, M.T., Jun, J.-H., Ashok, G., Patibandla, S.L., Dale, B.E. The ammonia freeze explosion (AFEX) process: A practical lignocellulose pretreatment.Appl. Biochem. Biotechnol. 1991, 28/29, $59-74$.

179. Alizadeh, H., Teymouri, F., Gilbert, T.I., Dale, B.E. Pretreatment of switch grass by ammonia fiber explosion (AFEX). Appl. Biochem.Biotechnol. 2005, 121 - 123, 1133-1141.

180. Kim, T.H., Lee, Y.Y. Pretreatment of corn stover by soaking in aqueous ammonia. Appl. Biochem. Biotechnol. 2005, 124, $1119-$ 1132.

181. Okano, K., Kitagaw, M., Sasaki, Y., Watanabe, T. Conversion of Japanese red cedar (Cryptomeria japonica) into a feed for ruminants by white - rot basidiomycetes. Animal Feed Sci. Technol. $2005,120,235-243$.

182. Lee, J. -W., Gwak, K. -S., Park, J.-Y., Park, M.-J., Choi, D.-H., Kwon, M., Choi, I.-G. Biological pretreatment of softwood Pinus densiflora by three white rot fungi. J. Microbiol. 2007, 45(6) , 485 $-491$.

183.Ge, H., Jensen, PD., Batstone, DJ. Pretreatment mechanisms during thermophilic - mesophilic temperature phased anaerobic digestion of primary sludge. Water Res 2010;44:123-30.

184. Ge, H., Jensen, PD., Batstone, DJ. Increased temperature in thermophilic stage in temperature phased anaerobic digestion (TPAD) improves degradability of waste activated sludge. Hazard Mater 2011;187:355-61.

185. Ge, H., Jensen, PD., Batstone, DJ. Temperature phased anaerobic digestion increases apparent hydrolysis rate for waste activated sludge. Water Res 2011;45:1597-606.

186. Bouallagui, H., Touhami, Y., Cheikh, RB., Hamdi, M. Bioreactor performance in anaerobic digestion of fruit and vegetable wastes: a review. Process Biochem 2005;40:989 - 95.

187. EPA - United States Environment Protection Agency. Biosolids technology factsheets, multistage anaerobic digestion. Ref. No. 832F06031, http://nepis.epa.gov/;2006

188. Bouallagui, H., Touhami, Y., Cheikh, RB., Hamdi, M. Bioreactor performance in anaerobic digestion of fruit and vegetable wastes. Process Biochem 2005;40:989 - 95.

189. Blonskaja, V., Menert, A., Vilu, R., Use of two stage anaerobic treatment for distillery waste. Adv Environ Res 2003;7:671-8.

190. Riau, V., De la Rubia MA., Perez, M. Assessment of solid retention time of a temperature phased anaerobic digestion system on performance and final sludge characteristics. J Chem Technol Biotechnol 2011;87:1074-82.

191. Verrier, D., Roy, F., Albagnac, G. Two-phase methanization of solid vegetable wastes. Biol wastes 1987;22:163-77.

192. Zhang, B., Zhang, SC., Shi, HZ., Cai, WM. The influence of pH on hydrolysis and acidogenesis of kitchen wastes in two-phase anaerobic digestion. Environ Technol 2005;26:329-39.

193. Wang, X., Zhao, Y. A bench scale study of fermentative hydrogen and methane production from food waste in integrated two-stage process. Int J Hydrogen Energy 2009;34:245-54.

194. Ueno, Y., Tatara, M., Fukui, H., Makiuchi, T., Goto, M., Sode, K. Production of hydrogen and methane from organic solid wastes by phase-separation of anaerobic process. Bioresour Technol 2007;98:1861-5.

195. Hatakka, A.I. Pretreatment of wheat straw by white-rot fungi for enzymatic saccharification of cellulose. Appl. Microbial. Biotechnol. 1983,18,350-357.

196. Ballesteros, I., Negro, M.J., Oliva, J.M., Canabas, A., Manzanares, P., Ballesteros, M. Ethanol production from steam explosion pretreated wheat straw. Appl. Biochem. Biotechnol. 2006, 70-72, 315.

197.[197]Miah, MS., Tada, C., Yang, Y. Aerobic thermophilic bacteria enhance biogas production. J Mater Cycl Waste Manage 2005;7:48-54.

198. Melamane, X., Tandlich, R., Burgess, J. Anaerobic digestion of fungally pretreated wine distillery wastewater. Afr J Biotechnol 2007;6:1990-3.

199. Akin, D.E., Rigsby, L.L., Sethuraman, A., Morrison, W.H., III; Gamble, G.R., Eriksson, K.E.L. Alterations in structure, chemistry and biodegradability of grass lignocellulose treated with the white rot fungiCeriporiopsis subvermispora and Cyathusstercoreus.Appl. Environ. Microbial. 1995,61,1591-1598.

200. Itoh, H.,Wada, M., Honda, Y., Kuwahara, M., Watanabe, T. Bioorganosolve pretreatments for simultaneous saccharification and fermentation of beech woods by ethanolysis and white rot fungi. J. Biotechnol. 2003, 103, 273-280.

201. Wichern, F., Miller, T., Joergensen, R.G., Buerkert, A. Effect of manure quality and application forms on soil $C$ and $N$ turnover of a 
Aritra Das, Chanchal Mondal and Shyamal Roy/

Journal of Engineering Science and Technology Review 8 (5) (2015) 141-165

subtropical oasis soil under laboratory conditions. Biol. Fertil. Soils 2004, 39, 165-171.

202. Schmit, KH., Ellis, TG. Comparison of temperature phased and other stage of the art process for anaerobic digestion of municipal solid waste. Water Environ Res 2001;73:314-21.

203.Sung, S., Harikashan, S. Performance of temperature-phased anaerobic digestion (TPAD) system treating dairy cattle wastes. Tamkang J Sci Eng 2001;4:301-10.

204. Lee, M., Hidaka, T., Hagiwara, W., Tsuno, H. Comparative performance and microbial diversity of hyper-thermophilic and thermophilic co-digestion of kitchen garbage and excess sludge. Bioresour Technol 2009;100:578-85.

205. Song, YC., Kwon, SJ., Woo, JH. Mesophilic and thermophilic temperature co-phase anaerobic digestion compared with singlephase mesophilic and thermophilic digestion of sewage sludge. Water Res 2004;38:1653-62.

206. Kim, T.H., J.S. Kim, et al. (2003): Pretreatment of corn stover by aqueous ammonia. Bioresource Technology 90(1): 39-47.

207. Kim, T.H. and Y.Y. Lee (2005): Pretreatment of corn stover by soaking in aqueous ammonia. Applied Biochemistry and Biotechnology - Part A Enzyme Engineering and Biotechnology 124(1-3): 1119-1131.

208. Kim, T.H., F. Taylor, et al. (2008): Bioethanol production from barley hull using SAA (soaking in aqueous ammonia) pretreatment. Bioresource Technology 99(13): 5694-5702.

209.Holtzapple, M.T., E.P. Ripley, et al. (1994): Saccharification, fermentation, and protein recovery from low-temperature AFEXtreated coastal bermudagrass. Biotechnology and Bioengineering 44(9): 1122-1131.

210. Rantwijk van (2003): Biocatalytic transformations in ionic liquids. Trends in Biotechnology, 21(3), 131-138.

211.Imai, M., K. Ikari, et al. (2004): High-performance hydrolysis of cellulose using mixed cellulase spe-cies and ultrasonication pretreatment. Biochemical Engineering Journal 17(2): 79-83.

212. Ahring, B.K., D. Licht, et al. (1999): Production of ethanol from wet oxidized wheat straw by Ther-moanaerobacter mathranii. Bioresource Technology 68(1): 3-9
213. Jorgensen, H., J.B. Kristensen, et al. (2007): Enzymatic conversion of lignocellulose into fermentable sugars: Challenges and opportunities. Biofuels Bioprod Bioref.

214. Schmidt, A.S., J. Puls, et al. (1996): Comparison of wet oxidation and steaming for solubilization of the hemicellulose fraction in wheat straw and birchwood. Biomass for Energy and the Environment, Vol. 3, Proc. 9th European Bioenergy Conf. 3: 15101515 .

215. Schmidt, A.S. and A.B. Thomsen (1998): Optimization of wet oxidation pretreatment of wheat straw. Bioresource Technology 64(2): 139-151.

216. Panagiotou, G. and L. Olsson (2007): Effect of compounds released during pretreatment of wheat straw on microbial growth and enzymatic hydrolysis rates. Biotechnology and Bioengineering 96(2): 250-258.

217. Klinke, H.B., B.K. Ahring, et al. (2002): Characterization of degradation products from alkaline wet oxidation of wheat straw. Bioresource Technology 82(1): 15-26.

\section{Reports and books}

218. Evans, G. "Liquid Transport Biofuels - Technlogy Status Report", "National Non-Food Crops Centre", 14-04-08.

219. "Biomass Feedstock for Slow Pyrolysis", BEST Pyrolysis, Inc website, BEST Energies, Inc.

220. Kirk-Otmer $4^{\text {th }}$ edition (2001), vol 5,13,15,20.

221. Twidell J., Weir T. Renewable Energy Resources. Published in USA by E. \& F.N. Spon. Copyright 1986. ISBN 0419 120009(hardback), 0419120106 (paperback).

222. Thermowood handbook, 2003.

223. Stelte, W. Steam explosion for biomass pretreatment, RK Report. Energy \& Climate. Centre for Renewable Energy and Transport, Section for Biomass, Danish Technological Institute.

224.Fengel, D., Wegner, G. Wood - Chemistry, Ultrastructure, Reactions. De Gruiter, Berlin, 1983. 